Document downloaded from:

http://hdl.handle.net/10251/65297

This paper must be cited as:

Jesús Benajes; J. Martín; García Martínez, A.; David; Warey Alok (2015). In-cylinder soot radiation heat transfer in direct-injection diesel engines. Energy Conversion and Management. 106:414-427. doi:10.1016/j.enconman.2015.09.059.

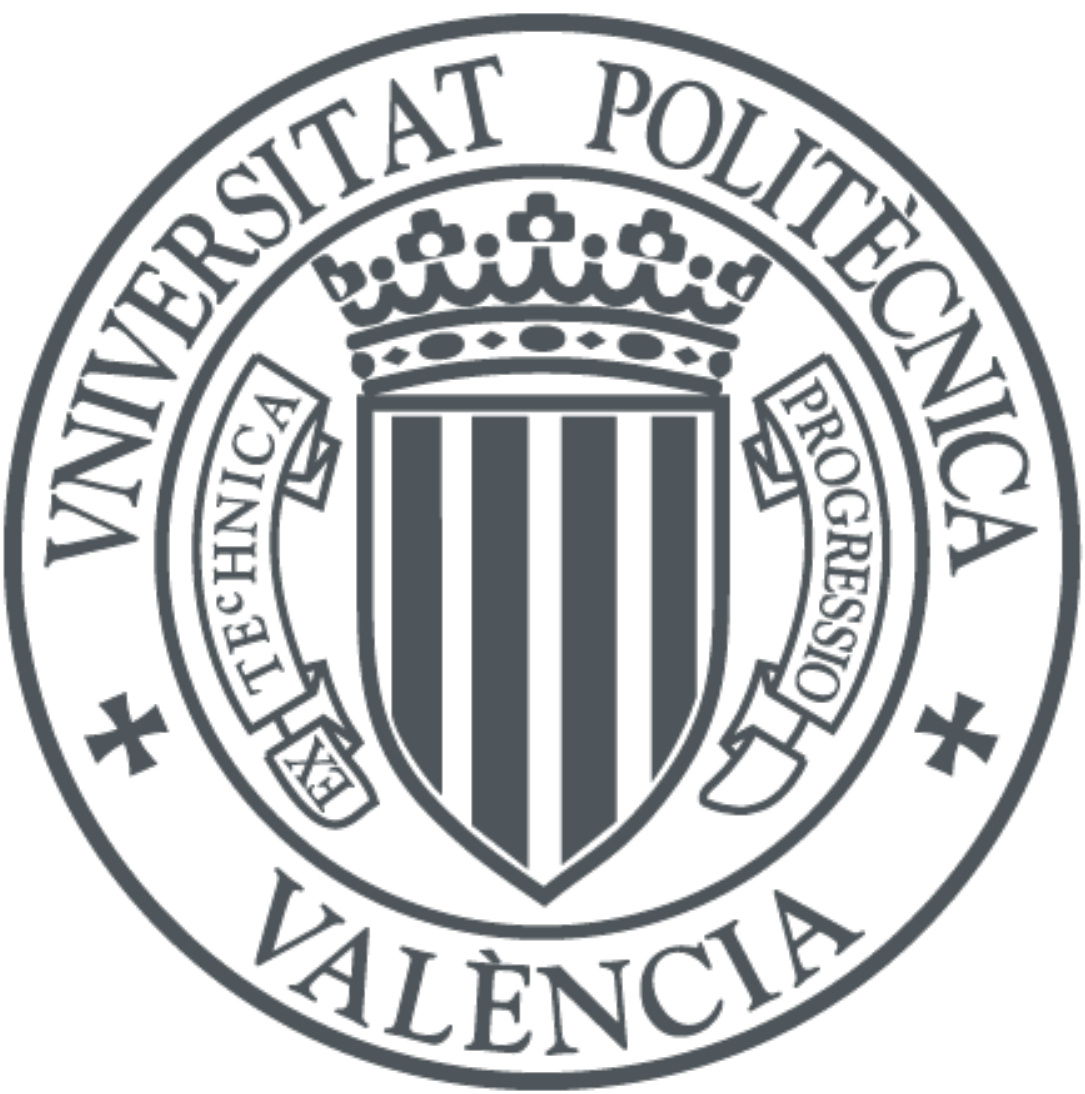

The final publication is available at

http://dx.doi.org/10.1016/j.enconman.2015.09.059

Copyright Elsevier

Additional Information 


\section{In-cylinder Soot Radiation Heat Transfer in Direct-Injection Diesel Engines}

\section{Authors:}

Jesús Benajes ${ }^{1}$, Jaime Martín ${ }^{1}$, Antonio García ${ }^{1}$, David Villalta ${ }^{1}$

Alok Warey $^{2}$

\section{Affiliation:}

1. CMT Motores Térmicos - Universitat Politècnica de València, Camino de Vera s/n, 46022, Valencia, Spain.

2. Propulsion Systems Research Lab, General Motors Global Research and Development.

\section{Corresponding Author:}

Dr. Antonio García

CMT - Motores Térmicos /Universitat Politècnica de València angarma8@mot.upv.es 


\section{HIGHLIGHTS}

Optoelectronic pyrometer provides similar results compared with a conventional method

Lower injection pressure results in higher radiation

Higher ambient temperature and higher in-cylinder gas density produce higher radiation

Larger lift-off length reduces the soot volume fraction and the spectral intensity

An increase on swirl number, load and CA50 provide a lower total radiation

Lower values of EGR implies a decreased on radiation intensity

\section{KEYWORDS}

Soot; in- cylinder heat transfer; radiation; Optical pyrometer;

\section{ABSTRACT}

The efficiency and $\mathrm{CO}_{2}$ are one of the main concerns of automotive manufacturers. There are several strategies under investigation to solve this problem. In the present work, the research effort has been focused on improving knowledge of in-cylinder heat transfer and its impact on engine efficiency. In particular, soot radiation was studied since it can be considered a significant source of the efficiency losses in modern diesel engines. Considering previous studies, the portion of total chemical energy released during combustion lost due to radiation heat transfer varies widely from 0.5 up to $10 \%$, depending on engine parameters and combustion process. Thus, the main objective of this work was to evaluate the amount of energy lost to soot radiation relative to the input fuel chemical energy during the combustion event under different operating conditions in a completely controlled environment provided by an optical engine. Under these simplified conditions, two-color method was applied by using high speed imaging pyrometer with cameras (two dimensional results) and optoelectronic pyrometer (zero dimensional results). Once a detailed comparison between both diagnostics was performed, optoelectronic pyrometer was used to characterize radiant energy losses in a fully instrumented 4-cylinder direct-injection light-duty diesel engine. In particular swirl ratio, EGR and combustion phasing effects on radiation heat transfer were evaluated. 


\section{INTRODUCTION}

The increasing concern due to the effect of GHG emissions is pushing the researchers and manufacturers to look for more efficient engines with lower fuel consumption and $\mathrm{CO}_{2}$ emissions. Thus, different strategies are proposed to achieve these objectives; thermal management improvement [1][2], indicated cycle optimization [3][4], incylinder heat transfer (HT) reduction [5][6], reduction of friction and auxiliaries losses [7][8], engine downsizing [9], new combustion concepts [10][11] among others. In the present work, the research effort has been focused on improving knowledge of incylinder heat transfer.

Combustion process in Direct Injection (DI) diesel engines includes different physical and chemical processes. During the turbulent diffusion flame, an important balance between soot formation and oxidation occurs in the spray. During oxidation process, the in-cylinder soot emission is luminous and generates an important source of radiant energy [12]. Carbon dioxide and water vapor molecules also emit radiation, however it is concentrated in a narrow spectral bands and its magnitude is assumed much smaller than soot particles. Moreover, radiation may also be emitted by many intermediate species formed during the combustion process, but since their concentration levels are small, their effect on radiation heat transfer is less important as is described in [13]. Thus, soot radiation can be considered a significant source of the efficiency losses in modern diesel engines [14]. In this sense, there are different studies in the literature, which quantify the amount of fuel chemical energy lost by soot radiation [14]. Depending on soot conditions, studies provide very different results. From 0.5-1\% [15] up to $5-10 \%[12][16]$ of the total chemical energy released during combustion process can be considered as radiant losses. Not only the amount of radiant fraction is a controversy, but also the contribution of radiation to the total heat transfer varies significantly as well from $11 \%$ up to $40 \%$ [12]. The significant differences between authors are directly related with the uniqueness of the radiant emission in each combustion system considering particular engine geometry and the operating conditions tested. Therefore, it could be stated that the relationship between all these combustion and engine parameters and its radiant emission is not fully understood currently.

The two-color pyrometry method has been used to determine radiation heat transfer along with the in-cylinder temperature and the soot volume fraction (using KL factor) 
from diesel engine flames [17][18]. A detailed description of the two-color pyrometry method can be found in [19]. Thus, pyrometry can be performed by using two different strategies; two dimensionally using a fast sampling high-speed camera [20][21] or zero dimensionally based on a collecting lens and an optical fiber in combination with a photo diode [14]. The first method provides spatial and temporal resolution of soot temperature and KL. Therefore, radiant emission can be calculated through this technique. This method is applied in particular to constant volume vessels, which can reproduce diesel engine like environment or in optical engines. The second method is applied in production engine experiments where the room for optical access to the combustion chamber is limited. The recorded signal in this case represents the spatially integrated information of a three dimensional complex phenomena which is characterized by significant gradients of spatial equivalence ratios and temperature along with the combination of reactive and non-reactive zones as well as different absorption coefficients and soot particle densities along the line of sight. [14]. Independent of the measurement technique method, there always exists some uncertainty of fouling impact from in-cylinder soot in the optical device or from occlusion of the field of view by geometric factors of the measurement system. Consequently, more research and efforts are needed in this field.

The main objective of this work was to evaluate the amount of energy to soot radiation relative to the input fuel chemical energy during the combustion event under different operating conditions in a completely controlled ambient provided by an optical engine. Under these simplified conditions, two-color method was applied by using high speed imaging pyrometer with cameras (two dimensional results) and optoelectronic pyrometer (zero dimensional results). Once a detailed comparison between both strategies was performed, an optoelectronic pyrometer was used to characterize radiant energy in a fully instrumented production 4-cylinder direct-injection light-duty diesel engine under several representative engine loads and speeds. In addition, the effect of swirl ratio, EGR rates and injection timing will be also shown.

\section{MATERIALS AND METHODS}

\subsection{Experimental test facilities}


Two different test benches were used to perform this work, an optically accessible single-cylinder engine and a multi-cylinder engine.

\subsubsection{Single-cylinder engine: optically accessible}

This facility was based on a 2-stroke single-cylinder direct-injection diesel engine (Jenbach JW 50). Further information can be found in [22]. The engine had a three liter displacement with $150 \mathrm{~mm}$ bore and $170 \mathrm{~mm}$ stroke. It was motored at low engine speed $(500 \mathrm{rpm})$. Intake and exhaust gas exchange was handled by ports in the liner. The cylinder head was specially designed to provide optical access to the combustion chamber. A cylindrical combustion chamber was designed to avoid spray wall impingement. The chamber had an upper port where the injector was mounted and four lateral accesses. One of these accesses was used for placing a high speed pressure transducer where as the other three were equipped with oval-shaped quartz windows, 88 $\mathrm{mm}$ length, $37 \mathrm{~mm}$ width and $28 \mathrm{~mm}$ thickness as shown in figure 1 . The cylinder head and the engine temperatures were controlled by means of a coolant loop. Coolant temperature was set to $353 \mathrm{~K}$ for all tests, to ensure good lubricant oil performance.

a)

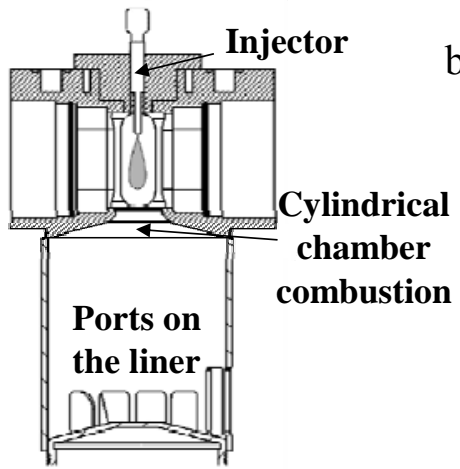

b)

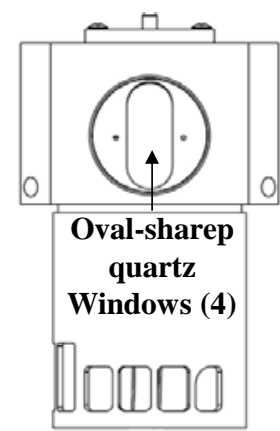

Figure 1. Scheme of the cylinder head and liner arrangement. a) Front view, b) Side view

In order to keep in-cylinder conditions constant (pressure and temperature), the engine was operated under skip-fired mode. One injection event took place every 30 cycles, which ensured that in-cylinder conditions were not influenced by residual gases from previous cycle.

A common-rail Bosch injection system was used along with a piezoelectric injector and a single-hole $140 \mu \mathrm{m}$ outlet diameter nozzle. The injector hole was $1 \mathrm{~mm}$ long with conical shape ( $\mathrm{K}_{\mathrm{s}}$ factor of 1.5$)$. The injected mass was relatively small compared to the volume of air utilized /the equivalence ratio is calculated in the section 3.1 and comes 
from 0.05 up to 0.09 ). Hence, it can be assumed that the thermodynamic conditions inside the combustion chamber were barely affected by the fuel evaporation. Due to the low injection frequency used during tests, the temperature of the injected fuel can be considered constant and controlled during the tests.

\subsubsection{Multi-cylinder Light Duty Diesel engine}

A production-type GM 1.9L Diesel engine was used for the second part of the study. The 4-cylinder engine uses a Common-Rail fuel injection system, variable geometry turbocharger (VGT), an exhaust gas recirculation system and an intake throttle valve. The engine had four valves per cylinder, centrally located injectors, and a re-entrant type combustion chamber. The swirl number was variable from 1.4 up to 3 and could be adjusted by a dedicated valve. All relevant engine data as well as injection system are given in table 1. This engine was set up with EURO IV calibration.

\begin{tabular}{|l|l|}
\hline Engine Type & $\begin{array}{l}\text { DI, 4-cylinder,charged,4- } \\
\text { stroke }\end{array}$ \\
\hline Displaced volume & $1900 \mathrm{cc}$ \\
\hline Stroke & $90.4 \mathrm{~mm}$ \\
\hline Bore & $82 \mathrm{~mm}$ \\
\hline Combustion Chamber & Re-entrant type \\
\hline Compression ratio & $17.5: 1$ \\
\hline Max. Power [kW] & 110 @4000rpm \\
\hline Max. Torque [Nm/min $\left.{ }^{-1}\right]$ & $320 / 2000-2750$ \\
\hline Injection System & $\begin{array}{l}\text { Bosch Common Rail } \\
\text { (solenoid) }\end{array}$ \\
\hline Max. Rail Pressure [bar] & 1600 \\
\hline Nozzle hole diameter [mm] & 0.141 \\
\hline Injector Nozzle Holes & 7 \\
\hline $\begin{array}{l}\text { Hydraulic flow rate }\left[\mathrm{cm}^{3}\right. \\
\text { (30s) at 100 bar] }\end{array}$ & 440 \\
\hline
\end{tabular}

Table 1. Engine and injection system specifications

The engine was directly coupled to an electric dynamometer that allowed control of the engine speed and load. The installation also included complete instrumentation to measure different fluid temperatures and mass flows. The list of the relevant instrumentation is given in table 2 .

\begin{tabular}{|l|l|l|}
\hline Variables to measure & Sensors & Range \\
\hline $\begin{array}{l}\text { Temperature of liquids } \\
\text { (coolant, oil, cooling } \\
\text { water at exchangers...) }\end{array}$ & $\begin{array}{l}\text { Thermoresistances } \\
(\mathrm{PT} 100)\end{array}$ & $-30-350{ }^{\circ} \mathrm{C}$ \\
\hline
\end{tabular}




\begin{tabular}{|l|l|l|}
\hline $\begin{array}{l}\text { Temperature of gases } \\
\text { (inlet and exhaust lines, } \\
\text { EGR...) }\end{array}$ & $\begin{array}{l}\text { K-type } \\
\text { Thermocouples }\end{array}$ & $-200-1250{ }^{\circ} \mathrm{C}$ \\
\hline Fuel mass flow & AVL 733s.18 & $0-41.67 \mathrm{~g} / \mathrm{s}$ \\
\hline Air mass flow & $\begin{array}{l}\text { AVL Flowsonix } \\
\text { Air }\end{array}$ & $0-1400 \mathrm{~kg} / \mathrm{h}$ \\
\hline Coolant Flow & DN25 Flow meter & $8.8-350 \mathrm{l} / \mathrm{min}$ \\
\hline Torque & Dynamometer & $0-500 \mathrm{Nm}$ \\
\hline In-cylinder pressure & Kistler 6125C10 & $0-300 \mathrm{bar}$. \\
\hline
\end{tabular}

Table 2. Test cell instrumentation

A combination of thermocouples and resistance temperature detectors (PT100) was selected to measure liquid and gas temperatures.

The in-cylinder pressure was measured for each cylinder with Kistler $6125 \mathrm{C} 10$ glowplug piezoelectric transducers and Kistler 4603B10 charge amplifiers. A crank angle increment of $0.5^{\circ}$ was used for the in-cylinder pressure acquisition [23], which was performed using DRIVVEN [24]. 25 consecutive cycles were measured.

The mean variables were acquired at a low sample frequency of $100 \mathrm{~Hz}$ using SAMARUC, a CMT-developed test system that collects the signals of different sensors and controls the electric dynamometer [25].

\subsection{In-cylinder pressure signal analysis}

The combustion analysis was performed with a single zone model named CALMEC, which is fully described in [26].This combustion diagnosis tool uses the in-cylinder pressure signal as its main input. The in-cylinder pressure was measured with its corresponding pressure transducer coupled with a charge amplifier for each engine. The pressure traces from engine cycles were recorded. Thus, each individual cycle's pressure data was smoothed using a Fourier series low-pass filter. Once filtered, the 25 collected cycles were ensemble averaged to yield a representative cylinder pressure trace, which was used to perform the analysis. Then, the first law of thermodynamics was applied between IVC (intake valve close) and EVO (exhaust valve open), considering the combustion chamber as an open system because of blow-by and fuel injection.

$$
R o H R=m c_{v} \frac{d T}{d \alpha}+\frac{d Q}{d \alpha}+p \frac{d V}{d \alpha}-\left(h_{f, i n j}-u_{f, g}\right) \frac{d m_{f, e v}}{d \alpha}+R T \frac{d m_{b b}}{d \alpha}
$$

Where $\alpha$ is the crank angle degree, $\mathrm{m}, \mathrm{dT}, \mathrm{dV}$ and $\mathrm{dQ}$ are the instantaneous mass in the chamber, gas temperature variation, volume variation and instantaneous heat transfer to 
the chamber walls respectively, $\mathrm{c}_{\mathrm{v}}$ is the specific heat which depends on the instantaneous temperature and composition, $\mathrm{dm}_{\mathrm{f}, \mathrm{ev}}$ is the variation of injected mass, $h_{f, i n j}$ and $u_{f, g}$ are the injected fuel enthalpy and internal energy of the evaporated fuel, $R$ is the gas constant and $\mathrm{dm}_{\mathrm{bb}}$ is the variation of blow-by leakage. Additionally, the heat transfer to the chamber wall $\mathrm{Q}$ together with a lumped conductance model allowed for accurate calculation of the RoHR.

The ideal gas equation of state was used to calculate the mean gas temperature in the chamber. Along with these two basic equations, several sub-models: a filling and emptying model was used to calculate the trapped mass [27]; the specific heat of the gas depends on both temperature and composition [28]; blow-by model was based on the evolution of the gas in an isentropic nozzle [26]; the chamber volume deformation due to pressure and inertia was calculated by means of a simple deformation model [29]; the heat transfer coefficient in the chamber walls was calculated with a modified Woschnilike model [30]:

$$
h=C D^{-0.2} p^{0.8} T^{-053}\left[C_{W 1} c_{m}+C_{W 2} c_{u}+C_{2} \frac{V_{d} T_{I V C}}{V_{I V C} p_{I V C}}\left(p-p_{0}\right)\right]^{0.8}
$$

where $C$ and $C_{2}$ are constants whose values are 0.12 and $0.001, c_{m}$ is the mean piston speed, $c_{u}$ is the instantaneous tangential velocity of the gas in the chamber that was adjusted using CFD calculations [30], $\mathrm{p}_{0}$ is the pressure during motoring conditions assuming a polytrophic evolution, and finally $\mathrm{C}_{\mathrm{W} 1}$ and $\mathrm{C}_{\mathrm{W} 2}$ are constants, whose values were adjusted for each engine by means of a combination of experimental and modelling methodology [31].

\subsection{Two color method}

This method was applied to two different optical setups - High Speed imaging and an Optoelectronic Pyrometer. Two color pyrometry is an optical thermometry technique that makes use of the presence of radiating soot inside the flame. The intensity of radiation emitted by soot particles $\left(\mathrm{I}_{\text {soot }}\right)$ is proportional to the radiation emitted by a black body at the same temperature $(\mathrm{T})$. This proportionality is determined by the emissivity of the particles, which can be expressed in terms of soot concentration, working wavelength $(\lambda)$ and a constant parameter $(\alpha)$ [32]. Therefore, $I_{\text {soot }}$ can be expressed as the following equation:

$$
I_{\text {soot }}(\lambda, T, K L)=\varepsilon_{\lambda} I_{b, \lambda}=\left[1-\exp \left(-\frac{K L_{2 C}}{\lambda^{\alpha}}\right)\right] \frac{1}{\lambda^{5}} \frac{c_{1}}{\left[\exp \left(\frac{c_{2}}{\lambda T}\right)-1\right]}
$$


Where $\mathrm{c}_{1}=1.1910439 \times 10^{-16} \mathrm{Wm}^{2} \mathrm{sr}^{-1}$ and $\mathrm{c}_{2}=1.4388 \times 10^{-2} \mathrm{mK}$. Zhao et al. [33] reported that $\alpha$ values are less dependent on the wavelength in the visible range than in the infrared.

In this regard, 550 and $650 \mathrm{~nm}$ with $\pm 10 \mathrm{~nm}$ FWHM were chosen when the method was used with two High-Speed CMOS cameras and 600 and $950 \mathrm{~nm}$ with $\pm 50 \mathrm{~nm}$ FWHM were used when the method was applied using the Optoelectronic Pyrometer. In this study $\alpha$ was assumed to be 1.39 , which is a commonly used for most of fuels [34]. The dependence of the emissivity on the soot amount within the optical path is usually expressed in terms of $\mathrm{KL}_{2 \mathrm{C}}=\mathrm{k}_{\text {soot }} \mathrm{L}$. This variable accounts for the total contribution of the soot along the optical path, independent of the soot distribution or geometrical size.

Two high speed cameras with two CMOS sensors were employed to measure soot radiation. The signal "S" depends on the detector spectral response, the radiation itself, the area $\mathrm{A}$ of the sooting flame within the field of view of the detector and the solid angle $\Omega$ subtended by the detector. Several simplifications can be applied [32], and a final expression (equation (4)) is obtained for each wavelength:

$$
S_{\lambda}=C_{\lambda} I_{\text {soot }}(\lambda, T, K L)
$$

Where $C_{\lambda}$ is a constant that takes into account $A, \Omega$ and $\lambda$. This parameter has to be calculated by means a radiance calibration procedure. For this purpose, calibration curves were obtained by means of a previously calibrated light source, as it is described by Payri et al. [32]. The slope of these curves is the transformation factor $\left(\mathrm{C}_{\lambda}\right)$ presented in equation (4).

\subsection{Optical set-up}

\subsubsection{High Speed Imaging Pyrometer}

The light emitted by the flame pass through a beam splitter which transmits and reflects $50 \%$ of the soot radiation to each of the two High-Speed CMOS cameras employed: a Phantom V12 for $650 \mathrm{~nm}$ and Photron SA5 for $550 \mathrm{~nm}$. Both cameras were equipped with a $100 \mathrm{~mm}$ focal length and $\mathrm{f} / 2$ lens. In order to ensure frame-to-frame synchronization, both cameras were connected in a Master/Slave mode. They were set to record at $15000 \mathrm{fps}$, with 5 to $8 \mu$ s exposure time for $650 \mathrm{~nm}$ and 8 to $12 \mu$ s for the $550 \mathrm{~nm}$, depending on test conditions. A scheme of the set-up is shown in figure 2. 


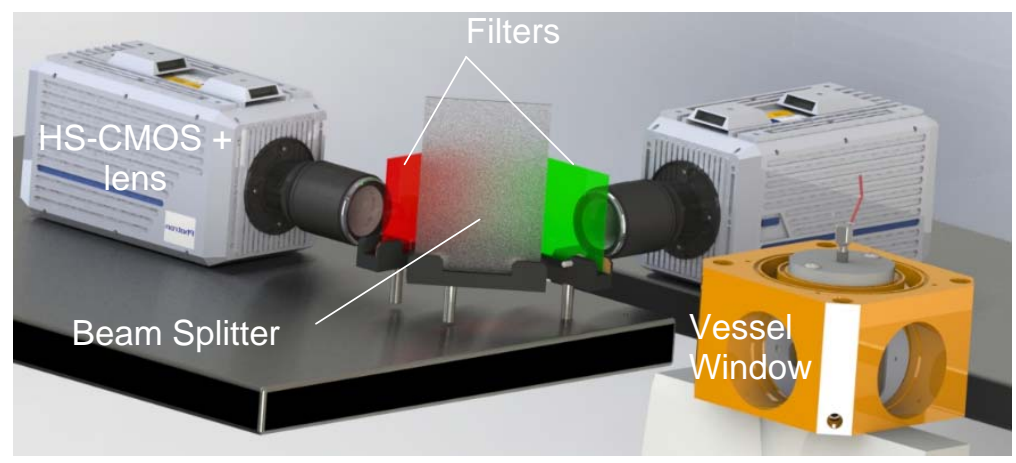

Figure 2: High Speed Imaging pyrometer Set-up

A spatial transformation is required to match both images pixel by pixel. A spatial transformation matrix was calculated, considering translation, rotation and scaling. For both images, background segmentation was also applied. A threshold value was obtained, considering a percentage of the total dynamic range of each image. The value of this percentage was set to $5 \%$ for all the tests performed, which has shown good accuracy on the flame boundary detection for all the tests. Only pixels with an intensity greater than the above mentioned $5 \%$ are considered part of the flame. Once both images are coupled, equation (3) was applied for each wavelength and $\mathrm{KL}_{2 \mathrm{C}}$ and temperature were obtained for each instant with a resolution of two spatial dimensions. In figure 3, an example of the application is shown.

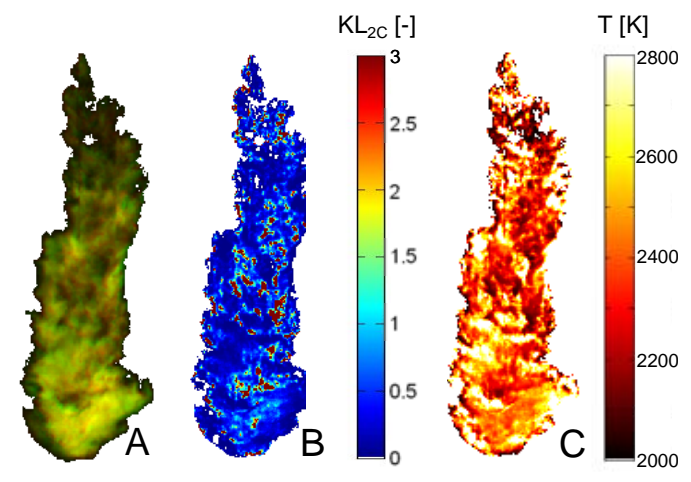

Figure 3. Composition of instantaneous soot natural luminosity at 550 and $650 \mathrm{~nm}$ (A) and the corresponding KL (B) and Temperature (C) distributions. Data was taken for 30\% Decane -70\% Hexadecane, at $\rho_{c}=23.4 \mathrm{~kg} / \mathrm{m}^{3}, T_{c}=800 \mathrm{~K}$ and $P_{\text {inj }}=50 \mathrm{MPa}$.

\subsubsection{Optoelectronic Pyrometer}

The in-cylinder soot radiation measurements were also performed with an optoelectronic signal converter with a selection of photodiodes and narrow band optical filters adapted to specific applications for combustion engine flame and radiation measurement. This light probe has been developed by AVL and is known as 
VisioFEM. A sapphire lens at the tip of the probe captures the light from the combustion chamber with a view angle of $90^{\circ}$. The soot radiation is conducted through optical fibers and is split to two filters at wavelengths of 600 and $950 \mathrm{~nm}$. Then, the photodiodes convert the intensity to a voltage signal. The signals from the photodiodes are amplified and recorded every $0.5^{\circ} \mathrm{CAD}$ aTDC. Signal conversion and signal conditioning ensures highest possible linearity of input radiation intensity to output signal voltage. The Optoelectronic raw signals and the absolute light intensities are linked by a calibration of the whole measurement chain using a halogen lamp, which provides a homogenously illuminated surrounding. A particular testing methodology is recommended by AVL with the aim of preventing the undesired errors in transmission due to soot deposits during a measurement campaign [35]. A schematic of the signal path from the flame to the data acquisition device is presented in figure 4.

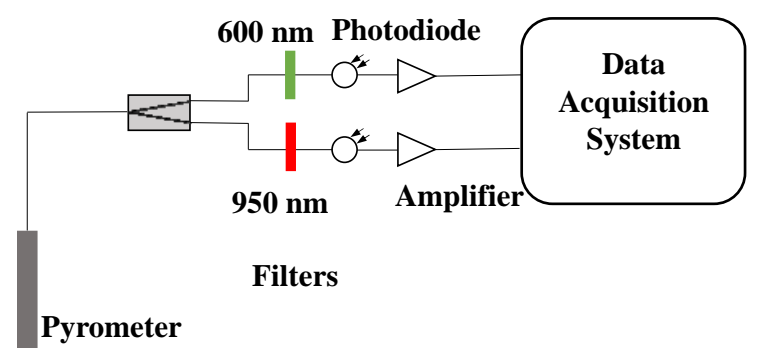

Figure 4. Signal path from flame to data acquisition device

Once both voltage signals are recorded, spectral intensity is obtained considering gain, transmission and sensitivity. Thus, once the voltage signal are converted, equation (3) is applied for each wavelength and $\mathrm{KL}_{2 \mathrm{C}}$ and temperature can be obtained at each instant. It is interesting to remark that with the Optoelectronic probe only temporal resolution is obtained for the soot temperature and KL results.

For the sake of clarity, figure 5 presents the optical set up when the optoelectronic pyrometer was used in both experimental engines.

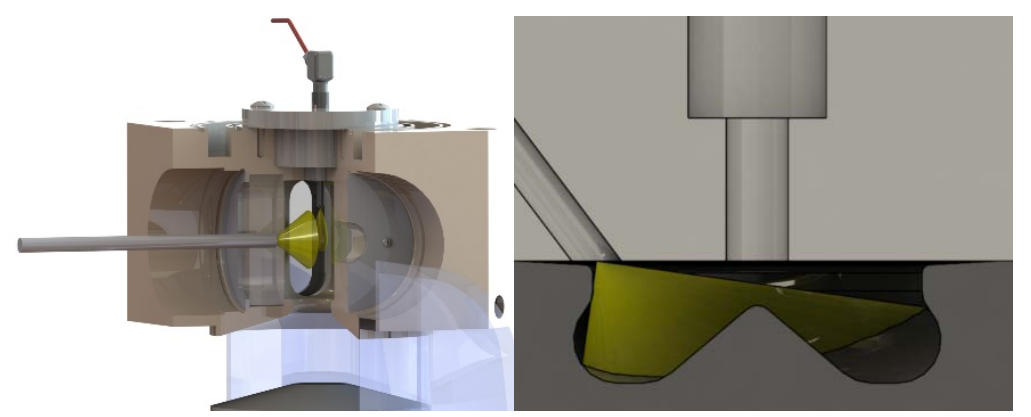

Figure 5 Optoelectronic pyrometer set up Left) Optical accessible engine configuration and Right) Light duty engine configuration 


\section{CHARACTERIZATION OF RADIATION UNDER OPTICAL ENGINE CONDITIONS}

The objective of this section is twofold. First, the effects of variations in different engine operating parameters on spectral intensity in a test rig with a completely controlled environment are presented. Second, some experiments were performed with the aim of evaluating the validation of the Optoelectronic Pyrometer (OP) versus a conventional optical set-up, High Speed Imaging Pyrometer (HSIP), in terms of KL and in-cylinder soot temperature. Then, an evaluation of the radiant fraction from the total energy supplied to the chamber is presented.

\subsection{Operating conditions}

The test matrix includes eight different engine operating conditions (table 3). The injected fuel mass was obtained with an injection rate meter. To determine the intake pressures and temperatures required for the test plan, an accurate characterization of the engine was performed, covering its full operation range. In-cylinder thermodynamic conditions were calculated from measured pressure, using first-law thermodynamic analysis. This analysis took into account blow-by, heat losses and mechanical deformations. The trapped mass was estimated using intake temperature and volume at EVC. Instantaneous in-cylinder temperature evolution during the cycle was calculated using the equation of state and correcting the trapped mass with blow-by estimations. Mechanical deformations can lead to a correction on instantaneous geometric volume; however, in this specific engine they have been neglected.

\begin{tabular}{|c|c|c|c|c|}
\hline $\begin{array}{c}\text { TDC } \\
\text { Temp. } \\
{[\mathbf{K}]}\end{array}$ & $\begin{array}{c}\text { TDC } \\
\text { Density } \\
{\left[\mathbf{k g} / \mathbf{m}^{3}\right]}\end{array}$ & $\begin{array}{c}\text { Injection } \\
\text { Pressure } \\
{[\text { bar] }}\end{array}$ & $\begin{array}{c}\text { Injected } \\
\text { fuel } \\
\text { mass } \\
{[\mathbf{m g} / \mathbf{s t k}]}\end{array}$ & $\begin{array}{c}\text { Equivalence } \\
\text { ratio [-] }\end{array}$ \\
\hline \multirow{3}{*}{800} & 23.4 & $\begin{array}{c}500 / 1000 \\
/ 1500\end{array}$ & $\begin{array}{c}13.4 / 20.3 \\
/ 25.4\end{array}$ & $\begin{array}{c}0.05 / 0.07 / \\
0.09\end{array}$ \\
\cline { 2 - 5 } & 18.9 & 1000 & 20.1 & 0.08 \\
\hline \multirow{3}{*}{900} & 23.4 & $\begin{array}{c}500 / 1000 \\
/ 1500\end{array}$ & $\begin{array}{c}13.4 / 20.3 \\
/ 25.4\end{array}$ & $\begin{array}{c}0.05 / 0.07 / \\
0.09\end{array}$ \\
\cline { 2 - 5 } & 18.9 & 1000 & 20.1 & 0.08 \\
\hline
\end{tabular}

Table 3. Experimental conditions optical engine

Energizing time was set to $2 \mathrm{~ms}$ for all conditions, which resulted in an approximate $4.5 \mathrm{~ms}$ hydraulic injection duration. The injector was triggered at $-6.05^{\circ}$ aTDC (SoE) and 
the injection started at $-5.9^{\circ}$ aTDC (SoI), to minimize variations of in-cylinder conditions during injection event. Each test was repeated 20 times to reduce measurement uncertainties due to engine operating variability as well as to improve signal-to-noise ratio.

In this work, one blend using two different fuels, n-decane and n-hexadecane, were employed. In fact, the fuel used was a blend of both single component fuels at a $30 \%$ $70 \%$ volume fraction. They were chosen due to their simplicity (pure fuels) and similarity with diesel fuel in terms of physical and chemical properties. Table 4 shows main fuel properties.

\begin{tabular}{|l|c|l|c|}
\hline Fuel & \multicolumn{3}{|c|}{$30 \% \mathbf{C}_{\mathbf{1 0}} \mathbf{H}_{\mathbf{2 2}}-\mathbf{7 0 \%} \mathbf{C}_{\mathbf{1 6}} \mathbf{H}_{\mathbf{3 4}}$} \\
\hline $\begin{array}{l}\text { Density @ 373 K } \\
{\left[\mathrm{kg} / \mathrm{m}^{3}\right]}\end{array}$ & 703.7 & $\begin{array}{l}\text { Dynamic } \\
\text { Viscosity @ } \\
373 \mathrm{~K}[\mathrm{mPa} \text { *s }]\end{array}$ & 6.67 \\
\hline $\begin{array}{l}\text { Derived Cetane } \\
\text { Number }\end{array}$ & 85.4 & $\begin{array}{l}\text { Vapor Pressure } \\
\text { at 373 K [kPa] }\end{array}$ & 7.72 \\
\hline $\mathrm{H} / \mathrm{C}$ & 2.15 & $\begin{array}{l}\text { Lower heating } \\
\text { value }[\mathrm{MJ} / \mathrm{kg}]\end{array}$ & 43.995 \\
\hline
\end{tabular}

Table 4. Fuel properties at 1 atm and $100^{\circ} \mathrm{C}$

\subsection{Effect of injection pressure, temperature and in- cylinder gas density on in-cylinder spectral intensity}

Figure 6 shows the temporal evolution of the spectral intensity $\left(\mathrm{I}_{\text {soot }}\right)$ measurements for High Speed Imaging Pyrometer (HSIP). In particular, sub-figure a) presents the injection pressure variation effects, sub-figure b) shows the in-cylinder gas density effects and finally, sub-figure c) describes ambient temperature effects on $\mathrm{I}_{\text {soot }}$. It is noted that the positive crank angle degree corresponds with CAD after TDC. It is interesting to remark that only values in the quasi steady state part of the diffusion combustion process are shown. In each sub-figure, curves represent the average of 20 fired cycles together with their standard deviation for $550 \mathrm{~nm}$ and $650 \mathrm{~nm}$. Thus, an average image per instant with spatial resolution is obtained and later, a spatial average of the complete image in each instant was performed. 
Independent of the wavelength, it can be stated that when higher injection pressure was used, lower $\mathrm{I}_{\text {soot }}$ was obtained. In the same way, use of lower in-cylinder gas density and temperature also provided lower spectral intensity. As it is expected, the higher the wavelength, higher the $I_{\text {soot }}$. Regarding measurements dispersion, higher the wavelength, higher the standard deviation.

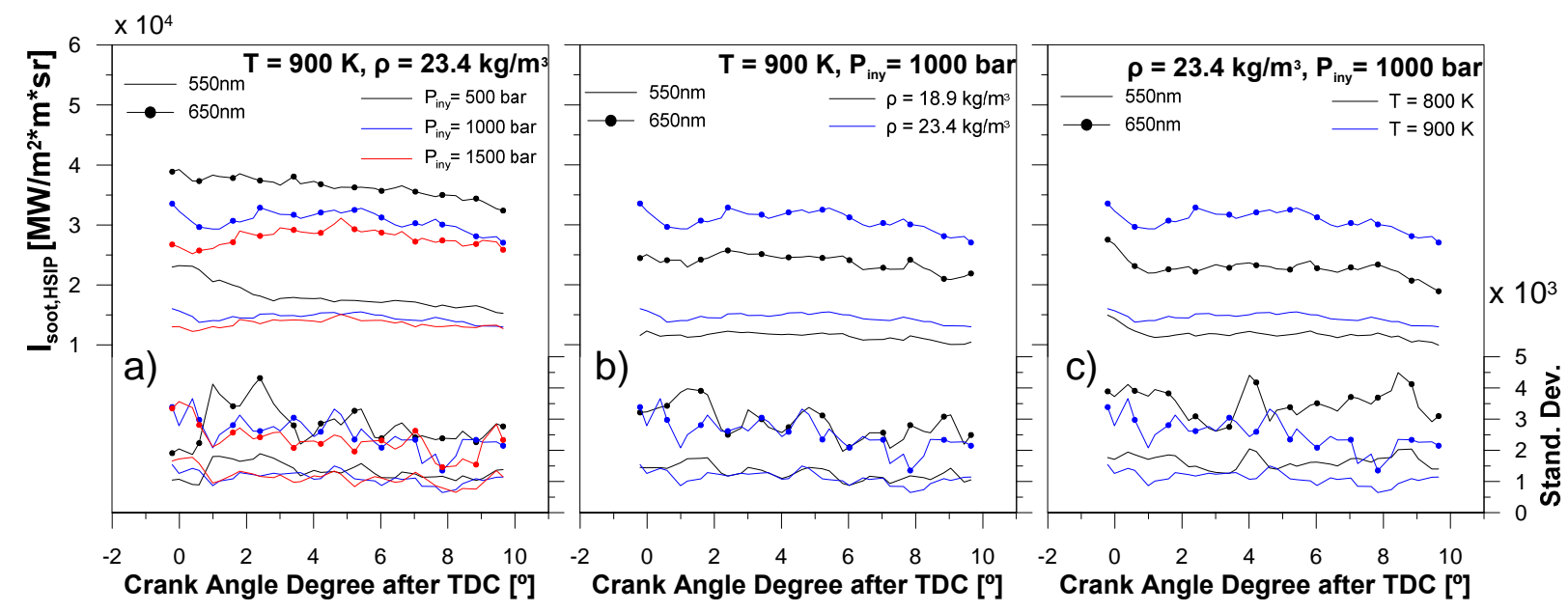

Figure 6. Temporal evolution of the spectral intensity for both 550nm and $650 \mathrm{~nm}$ wavelengths, and their corresponding standard deviation, a) Injection pressure effect; $b$ ) In-cylinder gas density effect; c)

Ambient temperature effect.

To provide further insight into the effect of injection pressure, in-cylinder gas density and ambient temperature on $\mathrm{I}_{\text {soot }}$, in figures 7,8 and 9 are represented the axial evolution of spectral intensity in the center line of the spray during quasy-steady state of combustion diffusion process along with the maximum spectral intensity at the flame lift-off length, LoLflame. This parameter is defined as the first axial position from the injector orifice where natural luminosity was acquired.

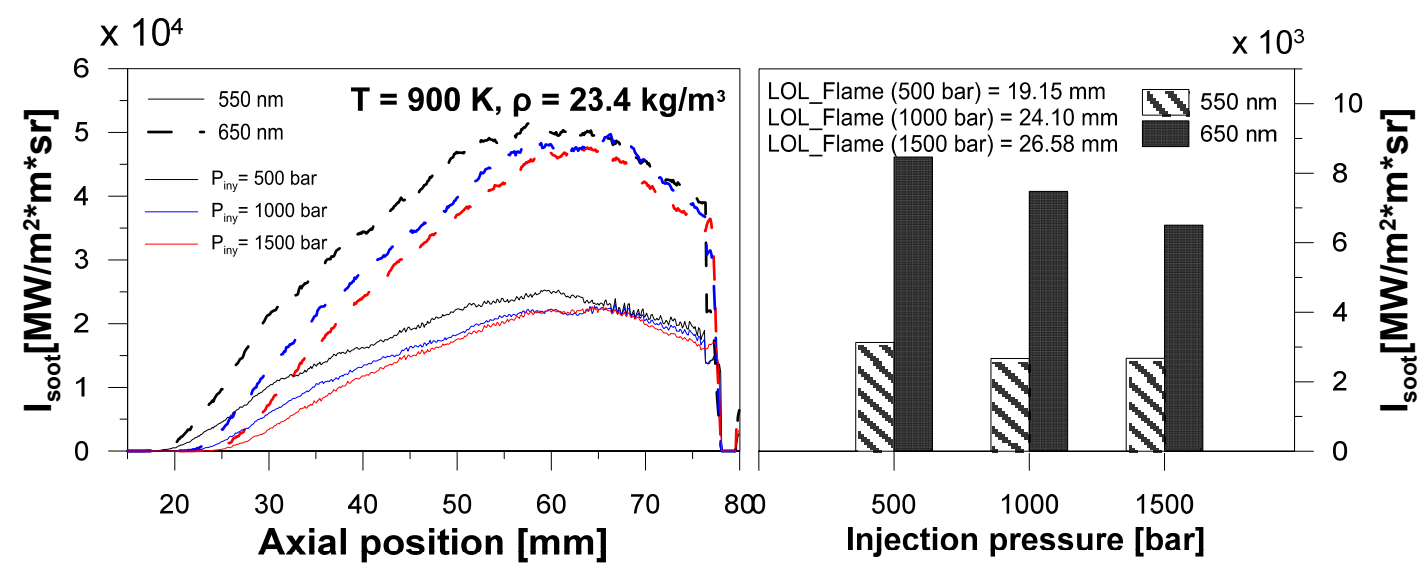

Figure 7. Axial evolution of spectral intensity in the center line of the spray together with the maximum value at the Flame Lift-off Length using three different injection pressures; 500, 1000 and 1500 bar. Incylinder gas density and ambient temperature were maintained constant. 
Considering figure 7, it can be stated that, independent of the axial position and wavelength tested, higher the injection pressure, lower the $\mathrm{I}_{\text {soot. }}$ Thus, when the injection pressure was reduced, the first occurances of natural luminosity moved closer to the injector implying a shorter flame lift-off length. Consequently the soot volume fractions increased [18][36]. In this sense, the peak of spectral intensity was also higher when the injection pressure was reduced as shown in figure 7. In fact, when the injection pressure was varied, no significant changes in the mixture fraction field were attained, nevertheless, it is well-known that the $\mathrm{OH}$ lift-off length is reduced due to a different balance between flow and flame velocities [36]. This behavior seems to be also valid for the LoLfLAme parameter.

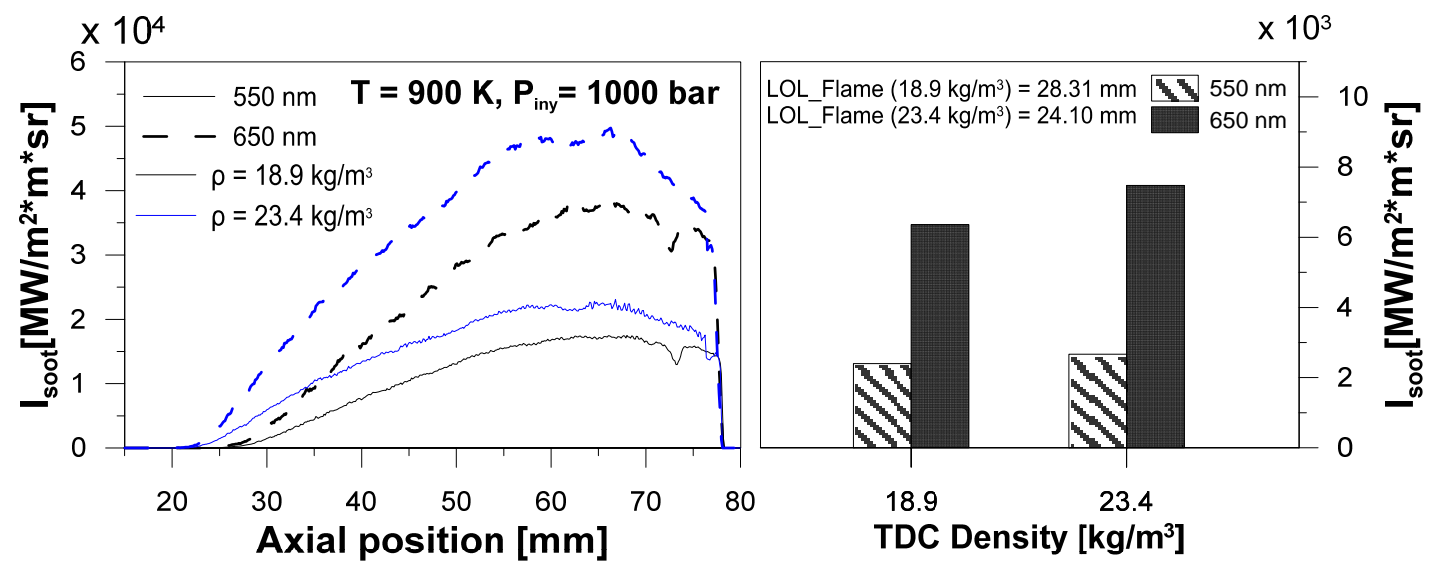

Figure 8. Axial evolution of spectral intensity in the center line of the spray together with the maximum value at the Flame Lift-off Length using two different ambient densities; 18.9 and $23.4 \mathrm{~kg} / \mathrm{m}^{3}$. Ambient temperature and injection pressure were maintained constant.

Figure 8 represents the axial evolution of spectral intensity at $550 \mathrm{~nm}$ and $650 \mathrm{~nm}$ in the center line of the spray together with the maximum spectral intensity value at the flame lift-off length under two different ambient densities; 18.9 and $23.4 \mathrm{~kg} / \mathrm{m}^{3}$. Ambient temperature and injection pressure were maintained constant at $900 \mathrm{~K}$ and $1000 \mathrm{bar}$ respectively. Thus, when in-cylinder gas density was decreased, the spectral intensity was also reduced independent of the wavelength tested as well as the axial position in the spray center line. The flame lift-off length moved farther from the injector hole and soot and the maximum spectral intensity were also reduced.

In addition, two cases varying the ambient temperature have been studied in figure 9 with the aim of examining its effect on $\mathrm{I}_{\text {soot }}$. In these cases, ambient temperature was reduced up to $800 \mathrm{~K}$ maintaining constant injection pressure, 1000 bar and in-cylinder gas density, $23.4 \mathrm{~kg} / \mathrm{m}^{3}$. Thus, when the ambient temperature was reduced, the radiance 
also decreased independently of the axial position for both wavelengths tested. In fact, the axial position of the maximum spectral intensity moved closer to the injector hole. This behavior implies a similar result as when the injection pressure was increased or the ambient temperature was reduced, the flame lift-off length was enlarged and therefore the amount of soot decreased as well as its spectral intensity.

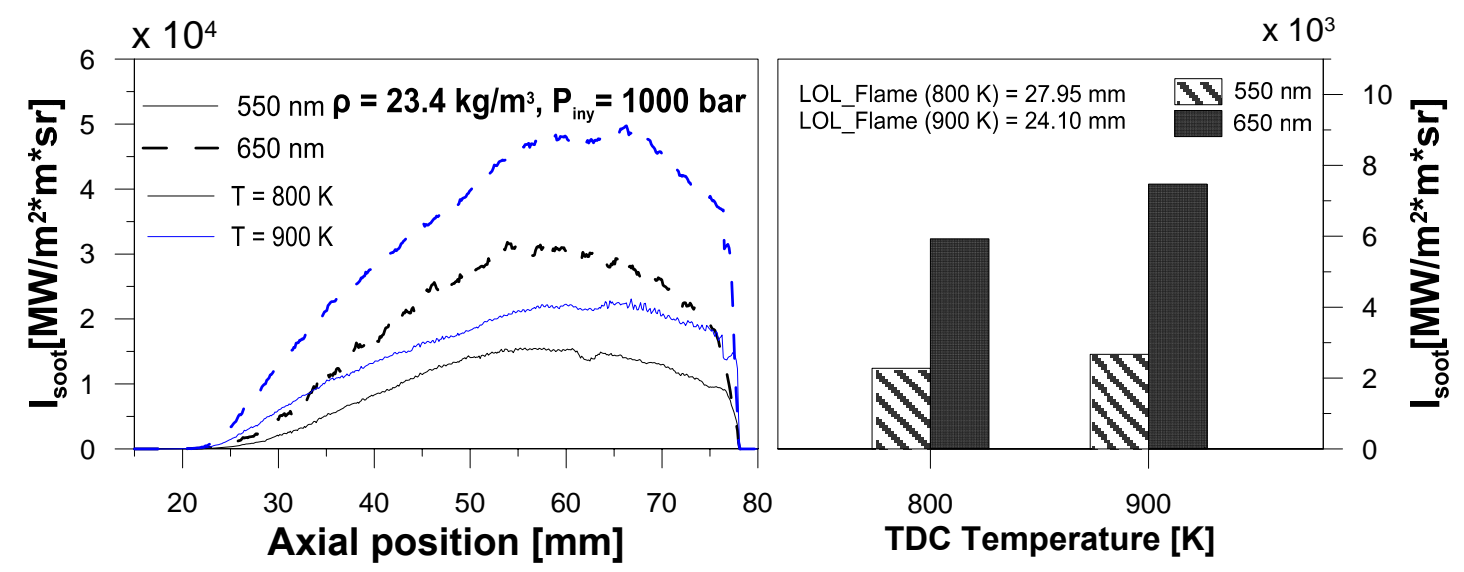

Figure 9. Axial evolution of spectral intensity in the center line of the spray together with the maximum value at the Flame Lift-off Length using two different ambient temperatures; $800 \mathrm{~K}$ and $900 \mathrm{~K}^{3}$. Incylinder gas density and injection pressure were maintained constant.

Once the effects of injection pressure, in-cylinder gas density and temperature on $\mathrm{I}_{\text {soot }}$ have been described it is necessary to evaluate and validate the Optoelectronic Pyrometer (OP) under similar conditions. Figure 10 shows the temporal evolution of the spectral intensity $\left(\mathrm{I}_{\text {soot }}\right)$ measurements for OP. Following similar analysis as the HSIP, three different sub-figures are presented, a) shows the injection pressure variation effects, b) presents the in-cylinder gas density effects and finally, c) is describes ambient temperature effects on $\mathrm{I}_{\text {soot }}$. Independent of the sub-figure, the profiles represented are the average of the same 20 fired cycles at each data point. Standard deviation of measured points is also shown in the same figures. The wavelengths used for this system were $600 \mathrm{~nm}$ and $950 \mathrm{~nm}$. This fact implied that a direct comparison with HSIP was not possible. Nevertheless, consistent results were obtained from the two different optical systems. An increase in ambient temperature and/or in-cylinder gas density as well as a decrease in the injection pressure implied higher spectral intensity. 


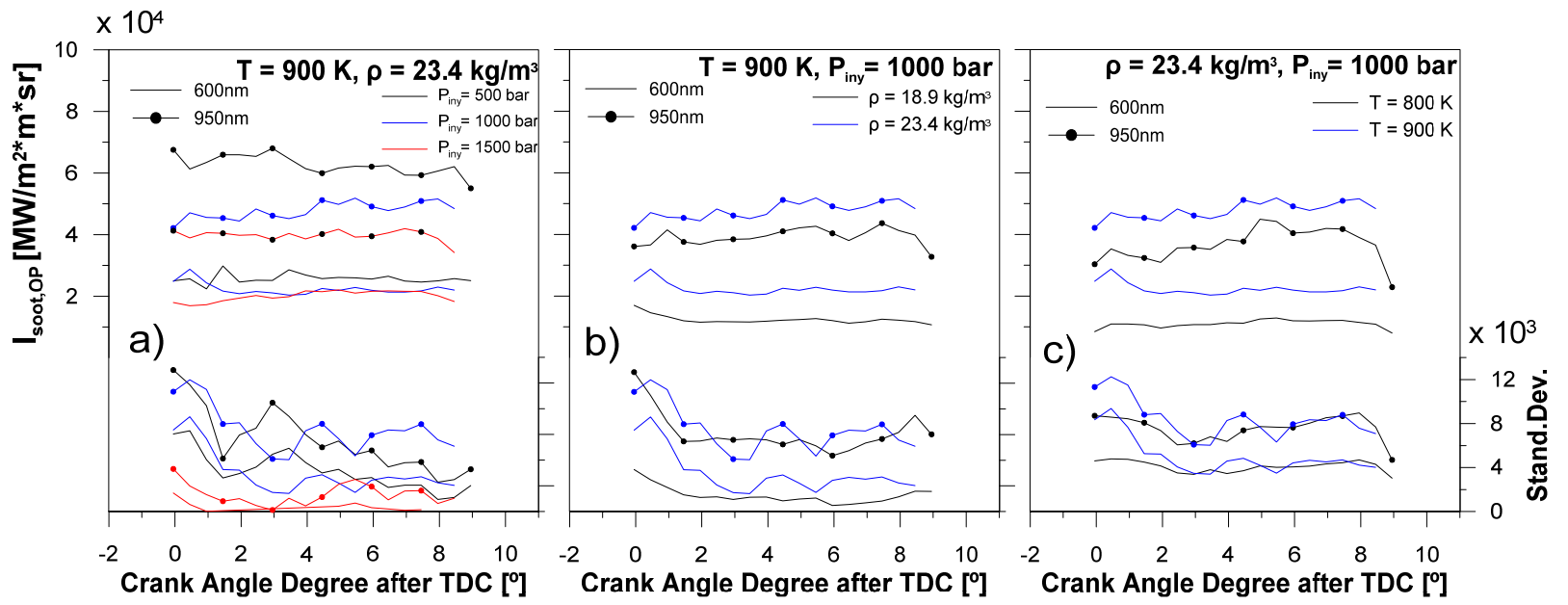

Figure 10. Temporal evolution of the spectral intensity for both $600 \mathrm{~nm}$ and $950 \mathrm{~nm}$ wavelengths, and their corresponding standard deviation, a) Injection pressure effect; b) In-cylinder gas density effect; c) Ambient temperature effect.

To compare both optical systems results, figure 11 shows the spectral intensity registered by HSIP and OP. In particular, an average value of the $\mathrm{I}_{\text {soot }}$ during the quasi steady state portion of diffusion combustion is shown along with its standard deviation. Thus, it can be stated that OP results follow similar trend as HSIP for the different operating conditions tested. Moreover, OP $600 \mathrm{~nm}$ results presented values quite close to HSIP $650 \mathrm{~nm}$ and $550 \mathrm{~nm}$ results. It is also interesting to remark that the dispersion obtained with OP was higher than with HSIP.
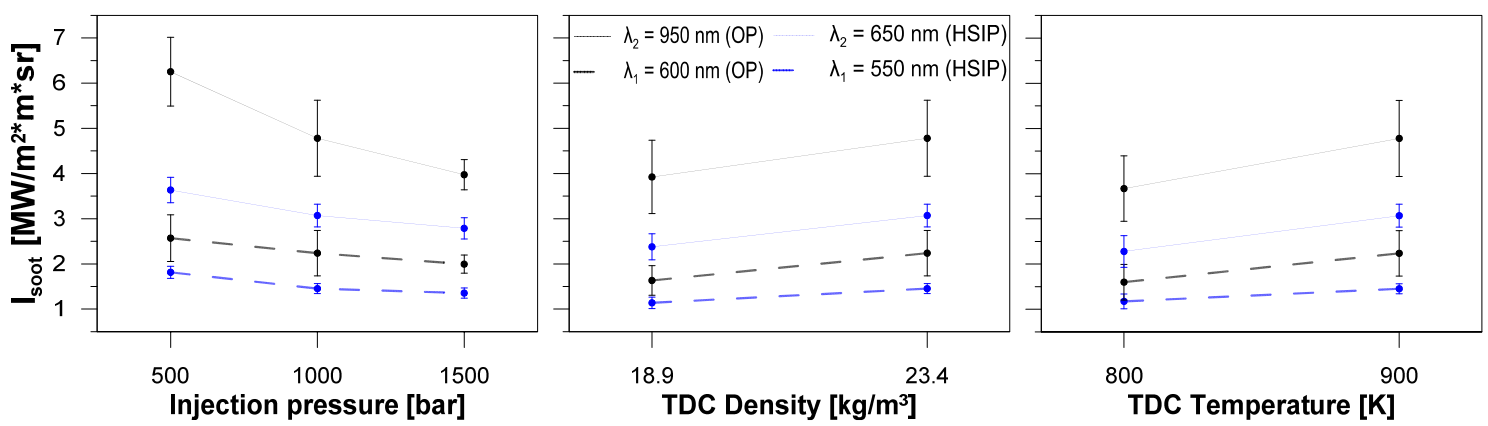

Figure 11: Average $I_{\text {soot }}$ during the quasy steady state of diffusion combustion and its standard deviation for HSIP and OP in each corresponding wavelengths measured a) Injection pressure effect; $b$ ) Incylinder gas density effect; c) Ambient temperature effect.

\subsection{Effect of injection pressure, ambient temperature and in-cylinder gas density on in-cylinder soot temperatures and optical thickness (KL)}

Figure 12 shows the temporal evolution of the soot temperature and optical thickness using equation (3) for High Speed Imaging Pyrometer (HSIP) along with their 
corresponding standard deviation. In particular, sub-figure a) presents the injection pressure variation effects, sub-figure b) shows the in-cylinder gas density effects and finally, sub-figure c) describes ambient temperature effects on KL and in-cylinder soot temperature. Adiabatic flame temperature was also included to compare with soot temperature at each operating point. Thus, adiabatic flame temperature was calculated with the assumption of constant pressure at each step of calculation, adiabatic burning of the stoichiometric fuel/air mixture and considering a conventional chemical equilibrium model, following the scheme proposed by Way [37].

Considering optical thickness results it can be stated that values obtained are from 0.15 up to almost 0.4 independent of the operating condition. Focusing on injection pressure effect it is shown that when the injection pressure is decreased, KL is increased. This behavior can be explained considering figure 7. Lower the injection pressure, shorter the flame lift-off length and higher the expected soot. Regarding in-cylinder gas density and temperature effects it is stated that lower in-cylinder gas density and/or temperature, results in lower KL. In this sense, figure 8 and 9 shows that a decrease in the in-cylinder gas density and/or temperature implies that the flame lift-off length moves farther from the injector hole and therefore the soot expected is also reduced in both cases.
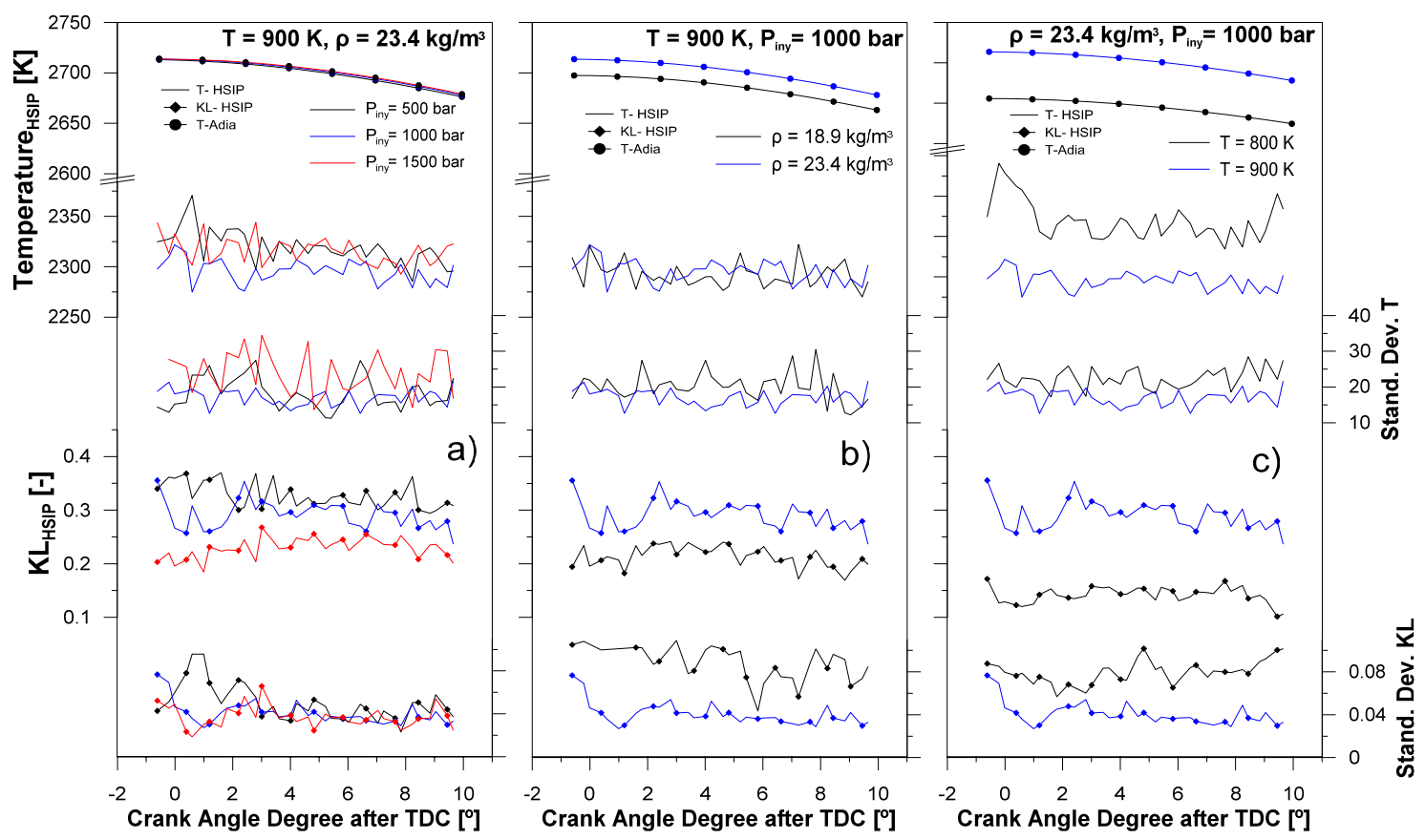

Figure 12: Average $I_{\text {soot }}$ during the quasy steady state of diffusion combustion and its standard deviation for HSIP and OP in each corresponding wavelengths measured a) Injection pressure effect; $b$ ) Incylinder gas density effect; c) Ambient temperature effect 
The soot temperature values are lower than the adiabatic flame temperature, by around $350 \mathrm{~K}$, This observation agrees with soot thermometry studies reported in the literature for diesel engines [38]. Soot thermometry measures the soot temperature, which is not exactly equivalent to the flame temperature in particular for diffusion flames. This fact does not imply that soot radiation has no influence on the peak flame temperatures. Radiative cooling from soot can reduce the gas temperatures in the sooting area, which are coupled to the high temperature flame by conductive heat transfer. [38]

Thus, soot temperature results for the three different injection pressures as well as for the two different ambient densities show quite similar values. This is because these operating conditions are low-radiation environments and consequently the impact of soot radiative heat transfer is similar and relatively minor for these particular conditions. By contrast, when the ambient temperature is increased, the soot temperature is also increased clearly. This behavior is completely expected considering the proportional dependency of the flame temperature on ambient temperature [37].

With the aim of comparing directly HSIP and OP, figure 13 presents the temporal evolution of KL and soot temperature differences between both optical systems and its standard deviation a) Injection pressure effect; b) In-cylinder gas density effect; c) Ambient temperature effect
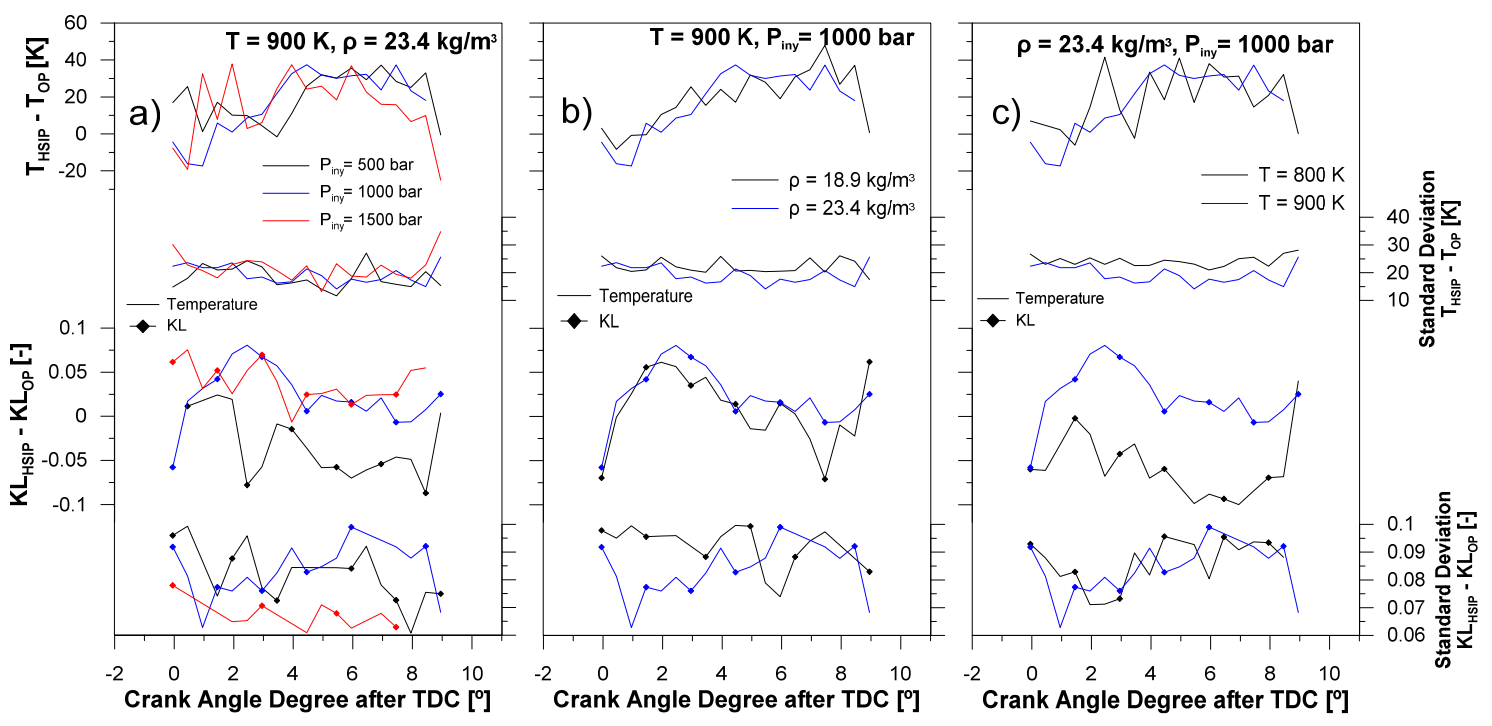

Figure 13: Temporal evolution of KL and soot temperature differences between HSIP and OP and its standard deviation for HSIP and OP a) Injection pressure effect; b) In-cylinder gas density effect; c) Ambient temperature effect 
Regarding optical thickness slight differences were attained comparing both optical systems. These discrepancies were higher when the soot generated was lower. Concerning soot temperature, in spite of higher differences between OP and HSIP, it should be clarified that in relative terms, this difference was even lower than in the case of KL. Thus, in general it can be stated that both systems present a similar response and therefore similar results are expected, consequently the validity of the OP versus HSIP has been demonstrated.

\subsection{Calculation of radiant fraction}

Considering the local soot temperature and optical thickness correspond to a blackbody spectral intensity $\left(\mathrm{I}_{\mathrm{b}, \lambda}\right)$ and soot spectral emissivity $\left(\varepsilon_{\lambda}\right)$ at each instant, the total radiation in Joules, $Q_{\mathrm{rad}}$, is given by equation (5)

$$
Q_{\text {rad }}=\pi \int_{t} \int_{A} \int_{\lambda} \varepsilon_{\lambda} I_{b, \lambda} d \lambda d A d t
$$

where $t$ represents the exposure time in which the optical system is registering flame luminosity, and $A$ is the flame area obtained by equation (6):

$$
A_{t}=2 \pi r \int_{x} d x
$$

where $r$ is the flame radius, which is determined from a temporal image of the flame and $d x$, is the axial widths. In this case, the axial width corresponds with one pixel.

It is worthy to note that radiation is also emitted by $\mathrm{CO}_{2}$ and $\mathrm{H}_{2} \mathrm{O}$ molecules but it is concentrated in a narrow spectral bands and its magnitude is assumed to be much smaller than that of soot particles [13]. Thus, as in Musculus [38] and Skeen [15], the radiant fraction, $X_{\text {rad }}$, is defined as the fraction of the total chemical energy released during injection that is lost due to radiation heat transfer. This is expressed as:

$$
X_{\text {rad }}=Q_{\text {rad }} / m_{f} Q_{L H V}
$$

where $m_{f}$ represents the mass of fuel injected and $Q_{L H V}$ is the lower heating value of $30 \%$ Decane and 70\% Hexadecane $(43995 \mathrm{KJ} / \mathrm{Kg})$. 
Figure 14 presents the radiant fraction results for the different operating conditions. Sub-figure a) shows the effect of injection pressure and ambient temperature. Sub-figure b) presents the effect of in-cylinder gas density variations. Considering soot temperature and KL obtained in previous section, expected trends of radiant fraction were attained. Thus, when the injection pressure was decreased and/or ambient temperature and/or incylinder gas density were increased, the radiant fraction was also increased.
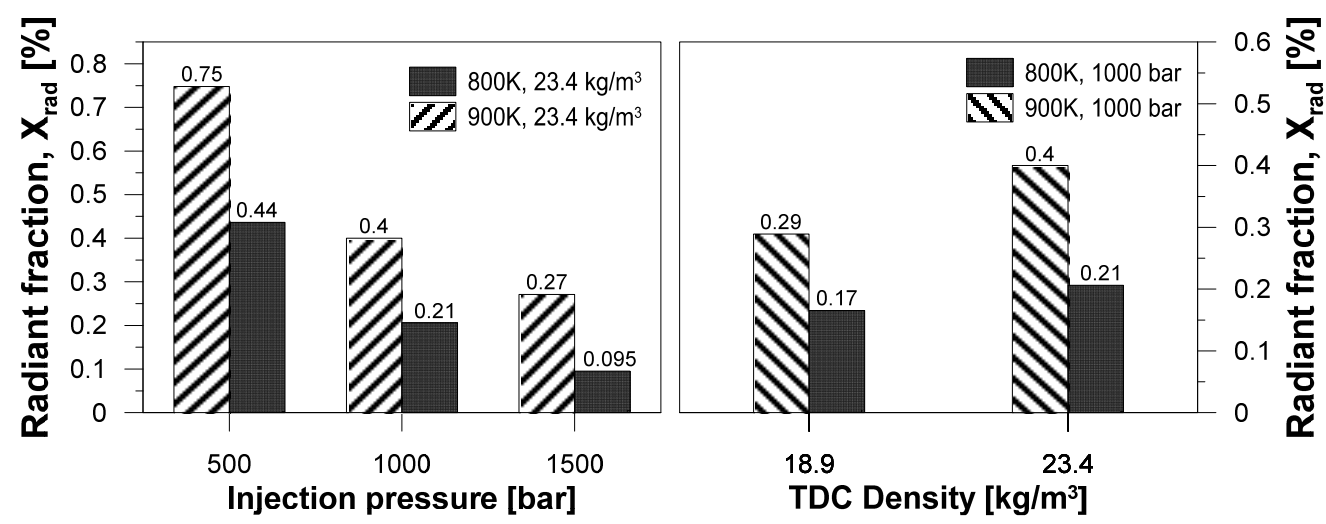

Figure 14: Radiant fraction a) effect of different injection pressures and ambient temperature; b) effect of different densities

Skeen [15] has presented results in a combustion vessel using an injector with single hole nozzle of $90 \mu \mathrm{m}$ nominal diameter, n-dodecane as fuel under ECN spray conditions $\left(1500\right.$ bar; $\left.\mathrm{X}_{\mathrm{O} 2}=15 \% ; \rho=22.8 \mathrm{~kg} / \mathrm{m}^{3}\right)$ and sweeping the ambient temperature. Thus, some operating conditions are quite similar to the ones presented in this research. For the conditions of Skeen's research, at $850 \mathrm{~K}$ ambient temperature the radiant fraction was $0.007 \%$ and at $900 \mathrm{~K}$ it was $0.068 \%$. Thus, results present similar values compared with those obtained in the present work. In particular, when higher injection pressure was used, the results presented in this study were similar to the ones presented by Skeen. Taking into account the significant differences in the experimental procedure, it is remarkable that there is consistency between the present work and the research performed by Skeen. It should also be remarkable that alkane blends tested were less prone to produce soot compared with a real diesel fuel, which should contain some aromatic compounds. Consequently, some slight underestimation in terms of radiant fraction was attained, although trends obtained under different operating conditions are correct.

Following similar analysis as Musculus [38] and Skeen [41] and with the aim of better understanding the consistency of radiant fraction results, figure 15 shows the theoretical 
maximum radiant fraction for the maximum soot temperature blackbody radiating during the whole injection process, $4.5 \mathrm{~ms}$, for each operating conditions. Thus, the maximum observed radiant fraction from the spectral data was approximately an order of magnitude less than that expected from the maximum soot temperature blackbody having the same surface area and emitting over the full injection hydraulic period.

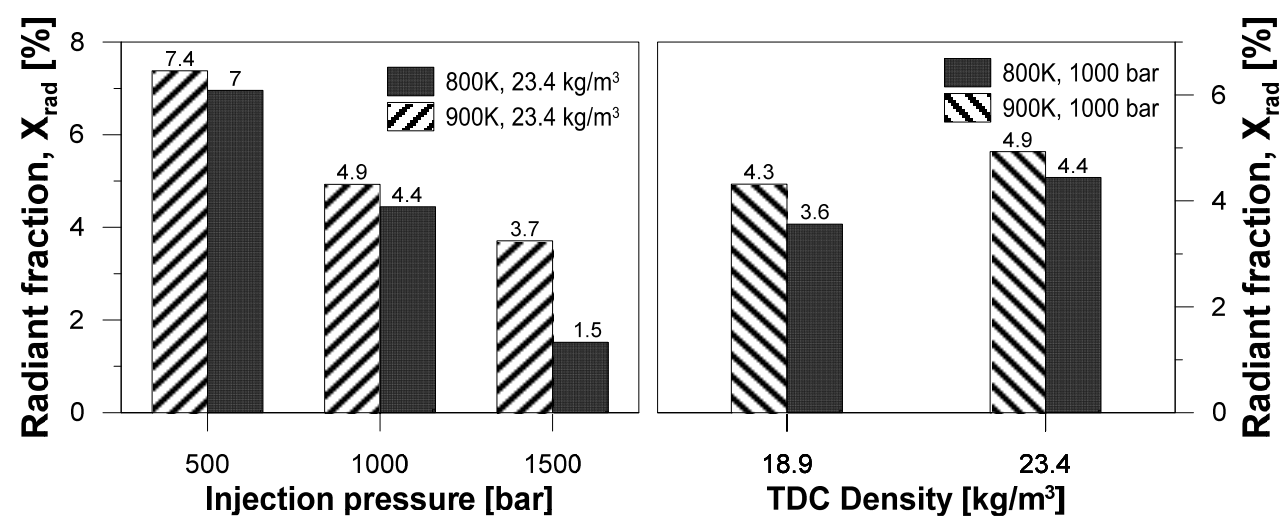

Figure 15: Theoretical maximum radiant fraction considering a blackbody flame a) effect of different injection pressures and ambient temperature; b) effect of different densities

Taking into account real soot cloud differences in terms of partial transparency and a probably smaller emitting area due to a considerable spacing between jets, the differences obtained between spectral data and the maximum soot temperature blackbody radiant fraction seem reasonable [38]. It is worthy to note that other studies of soot radiative heat transfer for higher-sooting conditions have reported much higher peak radiant fraction from $5-10 \%[12][16]$ than the ones showed in the present research. In this sense, it should be considered that in the optical engine very low load with low-shooting conditions are tested.

\section{CHARACTERIZATION OF RADIATION IN A LIGHT DUTY DIESEL ENGINE}

\subsection{Operating conditions}

Two different studies have been carried out. In a first step, an evaluation of the load effect on radiation, soot temperature and KL was performed. With this aim the engine was operated under conditions showed in table 5. In particular, CA50 was set constant at $13 \mathrm{CAD}$ aTDC and tests were developed without EGR. In addition, 100 engine cycles were recorded for each setting. 


\begin{tabular}{|l|c|c|c|c|}
\hline $\begin{array}{l}\text { Operation } \\
\text { condition }\end{array}$ & 2000@2 & 2000@5 & 1500@8 & 1500@14 \\
\hline Torque (Nm) & 38 & 82 & 133 & 220 \\
\hline $\begin{array}{l}\text { Injection } \\
\text { pressure (bar) }\end{array}$ & 450 & 649 & 735 & 1037 \\
\hline $\begin{array}{l}\text { Fuel Flow } \\
(\mathrm{kg} / \mathrm{min})\end{array}$ & 0.039 & 0.069 & 0.08 & 0.14 \\
\hline CA50 ( $\left.{ }^{\mathrm{a} a T D C}\right)$ & 13 & 13 & 13 & 13 \\
\hline $\mathrm{T}_{\text {in }}(\mathrm{K})$ & 315 & 317 & 318.5 & 318.4 \\
\hline $\mathrm{P}_{\text {in }}(\mathrm{bar})$ & 1.165 & 1.371 & 1.352 & 1.732 \\
\hline $\mathrm{P}_{\text {exh }}(\mathrm{bar})$ & 1.294 & 1.581 & 1.555 & 2.191 \\
\hline $\begin{array}{l}\text { Air Flow } \\
(\mathrm{kg} / \mathrm{min})\end{array}$ & 2.33 & 2.63 & 1.80 & 2.29 \\
\hline SN (-) & 1.4 & 1.4 & 1.4 & 1.4 \\
\hline EGR (\%) & 0 & 0 & 0 & 0 \\
\hline $\begin{array}{l}\text { Equivalence } \\
\text { ratio }\end{array}$ & 0.244 & 0.383 & 0.649 & 0.893 \\
\hline
\end{tabular}

Table 5. 4-cylinder engine operating conditions

In a second step, the effect of swirl ratio, EGR and injection timing (combustion phasing) were studied. With this purpose, the 2000@5 BMEP operating point was selected and the different settings were varied as shown in table 6 .

\begin{tabular}{|c|c|c|c|c|c|c|}
\hline $\begin{array}{l}\text { Operation } \\
\text { condition }\end{array}$ & $\mathrm{SN}=1.4$ & $\mathrm{SN}=3.0$ & $E G R=0 \%$ & $E G R=25 \%$ & $\mathrm{CA} 50=6^{\circ}$ & CA50 $=16^{\circ}$ \\
\hline Torque $(\mathrm{Nm})$ & 82 & 80 & 82 & 82 & 87 & 82 \\
\hline $\begin{array}{l}\text { Injection } \\
\text { pressure (bar) }\end{array}$ & 649 & 649 & 649 & 648 & 649 & 649 \\
\hline $\begin{array}{l}\text { Fuel Flow } \\
(\mathrm{kg} / \mathrm{min})\end{array}$ & 0.069 & 0.069 & 0.069 & 0.07 & 0.07 & 0.071 \\
\hline CA50 ( $\left.{ }^{\circ} \mathrm{aTDC}\right)$ & 13 & 13 & 13 & 13 & 6 & 16 \\
\hline $\mathrm{T}_{\text {in }}(\mathrm{K})$ & 317 & 316.8 & 317 & 318 & 316.2 & 317.9 \\
\hline $\mathrm{P}_{\text {in }}$ (bar) & 1.371 & 1.350 & 1.371 & 1.365 & 1.364 & 1.357 \\
\hline $\mathrm{P}_{\mathrm{exh}}$ (bar) & 1.581 & 1.529 & 1.581 & 1.808 & 1.602 & 1.520 \\
\hline $\begin{array}{l}\text { Air Flow } \\
(\mathrm{kg} / \mathrm{min})\end{array}$ & 2.63 & 2.47 & 2.63 & 1.95 & 2.55 & 2.57 \\
\hline SN (-) & 1.4 & 3 & 1.4 & 1.4 & 1.4 & 1.4 \\
\hline EGR (\%) & 0 & 0 & 0 & 25 & 0 & 0 \\
\hline $\begin{array}{l}\text { Equivalence } \\
\text { ratio }\end{array}$ & 0.383 & 0.408 & 0.383 & 0.524 & 0.401 & 0.403 \\
\hline
\end{tabular}

Table 6.4-cylinder engine operating conditions for 2000@5 operating point

Commercially available European diesel fuel was used in this part of the work. Table 7 shows the main characteristics of the fuel used. 


\begin{tabular}{|l|c|l|c|}
\hline Fuel & \multicolumn{2}{|c|}{ Diesel } \\
\hline $\begin{array}{l}\text { Density @373 K } \\
{\left[\mathrm{kg} / \mathrm{m}^{3}\right]}\end{array}$ & 821.5 & $\begin{array}{l}\text { Dynamic Viscosity } \\
\text { @ 373 K [mPa* }]\end{array}$ & 2.7 \\
\hline $\begin{array}{l}\text { Derived Cetane } \\
\text { Number }\end{array}$ & 50.8 & $\begin{array}{l}\text { Molecular Weight } \\
{[\mathrm{kg} / \mathrm{kmol}]}\end{array}$ & 215.42 \\
\hline C/H by weight & 6.05 & $\begin{array}{l}\text { Lower heating value } \\
{[\mathrm{MJ} / \mathrm{kg}]}\end{array}$ & 43.995 \\
\hline
\end{tabular}

Table 7. Fuel properties at 1 atm and $40^{\circ} \mathrm{C}$

\subsection{Influence of load, swirl ratio, EGR and combustion phasing on in-cylinder soot temperature, $\mathrm{KL}$ and radiation intensity}

In this section, the Optoelectronic Pyrometer was used to evaluate the radiation intensity, soot temperature and optical thickness in a multi-cylinder engine. Figure 16 shows an example of the raw data obtained with the Optoelectronic Pyrometer. The temporal evolution of the spectral intensity $\left(\mathrm{MW} / \mathrm{m}^{2 *} \mathrm{~m}^{*} \mathrm{sr}\right)$ at both wavelengths, 600 $\mathrm{nm}$ and $950 \mathrm{~nm}$ is shown for the $1500 \mathrm{rpm}$ and 8 bar BMEP case. Each curve represents the average and the standard deviation of 100 cycles recorded.

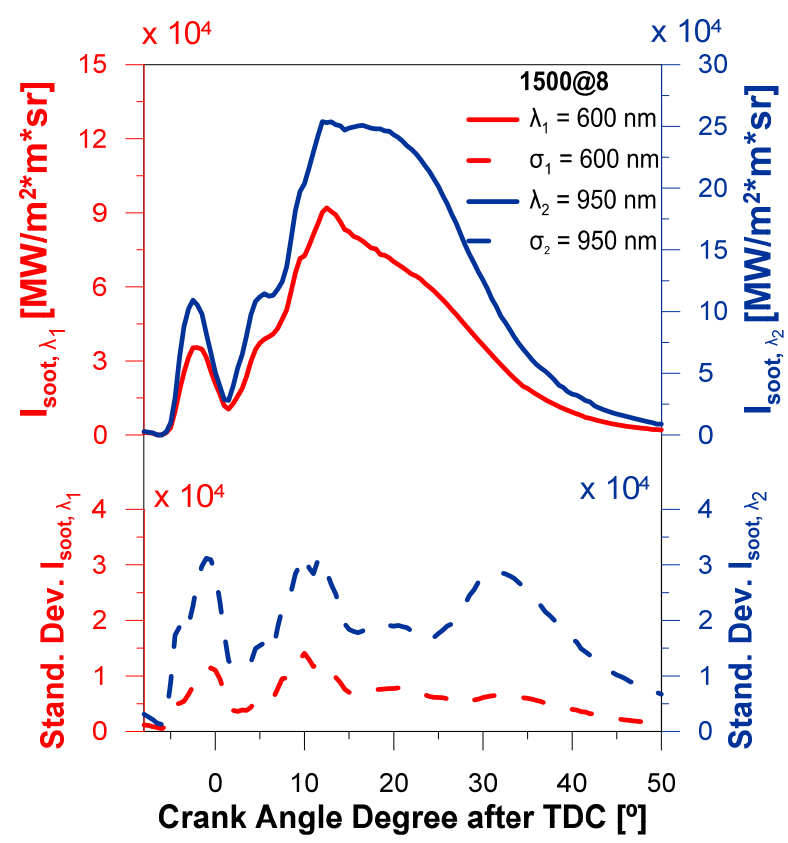

Figure 16. Temporal evolution of the spectral intensity using Optoelectronic Pyrometer at 1500 rpm and 8 bar BMEP. 
Figure 17 shows the temporal evolution of rate of heat release, radiation intensity, soot temperature and optical thickness KL. Sub figure a) shows a comparison between 8 and 14 bar BMEP cases at $1500 \mathrm{rpm}$. Sub figure b) presents a similar comparison but in these cases at low load conditions, 2 and 5 bar BMEP at $2000 \mathrm{rpm}$. It is interesting to note that these tests were performed maintaining constant the CA50 at 13 CAD aTDC, without EGR and with a constant swirl ratio of 1.4. Different curves represent the average and standard deviation of 100 cycles. Injection rate profile was simulated from a particular sub-model included in CALMEC [26] which has been calibrated to the injector and nozzle used in the present research. Thus, the end of injection for each test is marked with a vertical straight line. In addition, it should be also noted that radiation intensity is the spectral intensity integrated from $300 \mathrm{~nm}$ up to $3000 \mathrm{~nm}$.

In general, it is possible to state that there were clear differences in radiation intensity profiles considering engine speed and overall load. Nevertheless, there was also some similarity in the temporal evolution of the different radiation intensity traces. For the same engine speed, shape and slopes were quite similar although the peak was different and higher when the load was increased. The range of the peak values varied from 0.15 $\mathrm{MW} / \mathrm{m}^{2}$ up to $1.6 \mathrm{MW} / \mathrm{m}^{2}$. Comparing these results with other radiation intensity studies, in particular Soloiu [39], radiation intensity peaks found in the literature are in the same order of magnitude that the ones presented in the current work $(0.76$ $\mathrm{MW} / \mathrm{m} 2$ ), taking account the significant differences in the experimental procedure. Regarding soot temperature curves, for the same engine speed quite similar evolution was attained. In terms of the peak values range for the different operating conditions tested, soot temperature varies from $2600 \mathrm{~K}$ up to $2400 \mathrm{~K}$. A clear decrease in the temperature was attained when the engine load was decreased. Moreover, soot temperature values were consistent with other studies in similar conditions [12][38]. KL profiles were quite similar there existed and seem to be governed by the diffusion combustion. In this sense, the greater the diffusion phase in the RoHR, the higher the amount of soot. The range of the peak values varied from 0.25 up to almost 1.75 . When the injection process ended, a sudden decrease in KL signal was obtained. The maximum peak of the optical thickness traces almost coincided with the end of injection. After the end of injection, the oxidation process governs soot emissions and therefore the soot formation reaches at its maximum value [40]. Thus, when the load was increased the soot formation also increased. This behavior was shown even 
considering other cross effects. For instance, in the $1500 \mathrm{rpm}$ cases, the CA 50 and EGR were constant for both loads tested ( 8 and 14 bar BMEP). By contrast, the injection pressure was higher when the load was increased (table 5), and therefore reduced soot formation could be expected. Nevertheless, considering in-cylinder measurements, the effect of higher equivalence ratio due to higher load seems to govern the total soot formation and consequently, higher equivalence ratio provides higher soot formation. Considering RoHR traces, it can be stated that the radiation intensity starts with the RoHR and the maximum peak intensity of both curves are almost coincident. The end of radiation traces go to zero at similar crank angle degree as the RoHR.
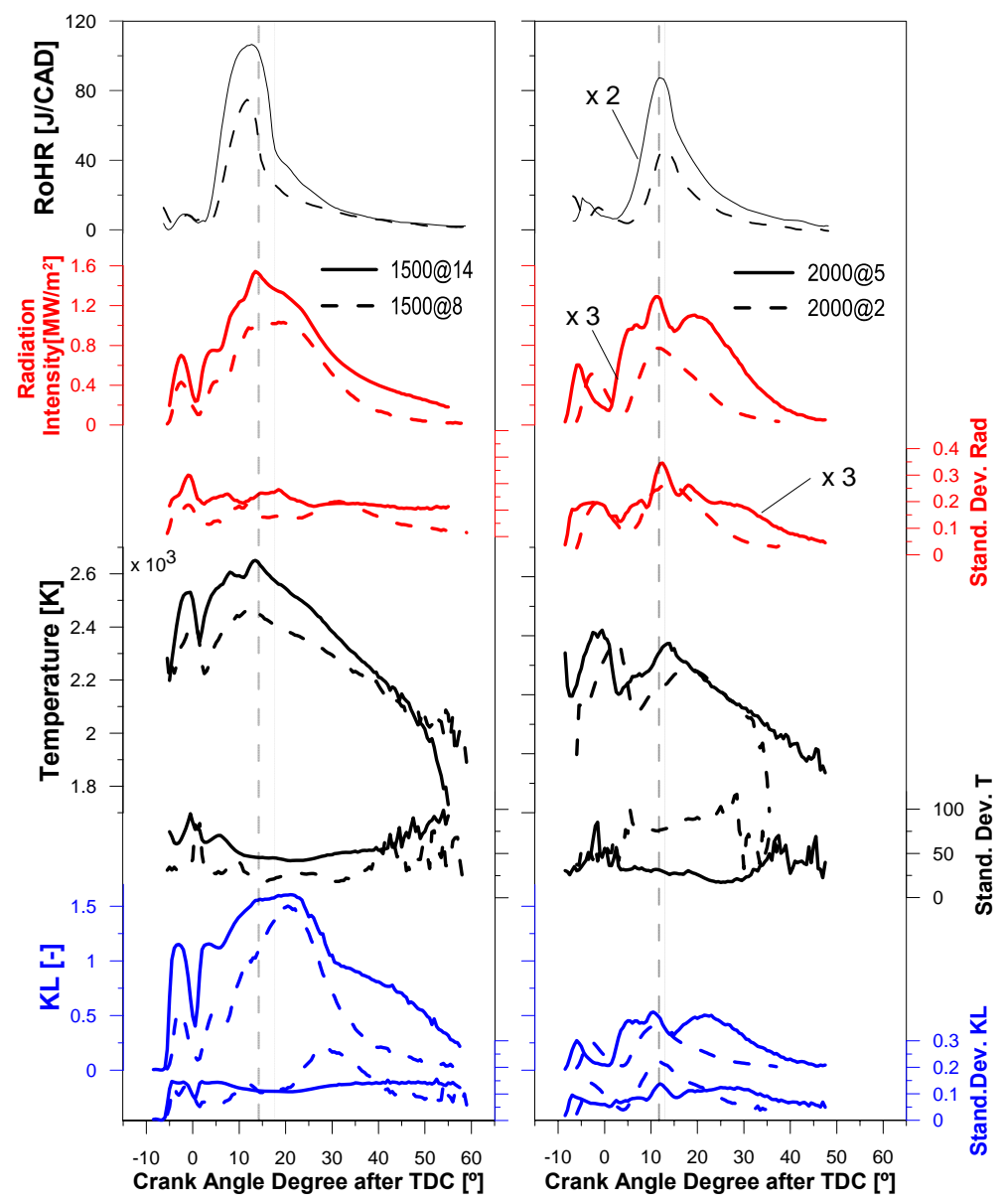

Figure 17. Temporal evolution of radiation intensity, soot temperature and KL; a) $1500 \mathrm{rpm}$ comparing 8 and 14 bar bmep; b) 2000 rpm comparing 2 and 5 bar BMEP. For each studied case, the end of injection, is marked with a vertical line. CA50, Swirl ratio and EGR were constant.

To provide a direct comparison and with the aim of validating previous discussions, figure 18 presents the total radiation for different load operating conditions. It should be also noted that the total radiation is the radiation intensity integrated during the whole 
temporal evolution. Thus, an increase in load clearly shows an increase in total radiation.

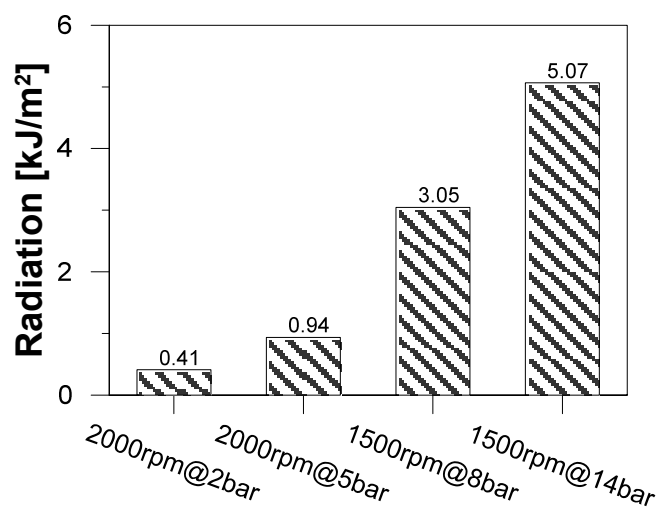

Figure 18. Total radiation for different load operating conditions.

Figure 19 presents the temporal evolution of radiation intensity, soot temperature and optical thickness KL for the case of $2000 \mathrm{rpm}$ and 5 bar BMEP. Sub-figure a) shows the isolated effects of swirl ratio maintaining constant the CA50 at 13 CAD aTDC and without EGR. Sub-figure b) presents the EGR effects maintaining constant the SN at 1.4 and CA50 at 13 CAD aTDC. And finally, sub-figure c) presents the effects of CA50 keeping constant $\mathrm{SN}$ at 1.4 and without EGR. As previous figures, different curves represent the average and standard deviation of 100 cycles. 

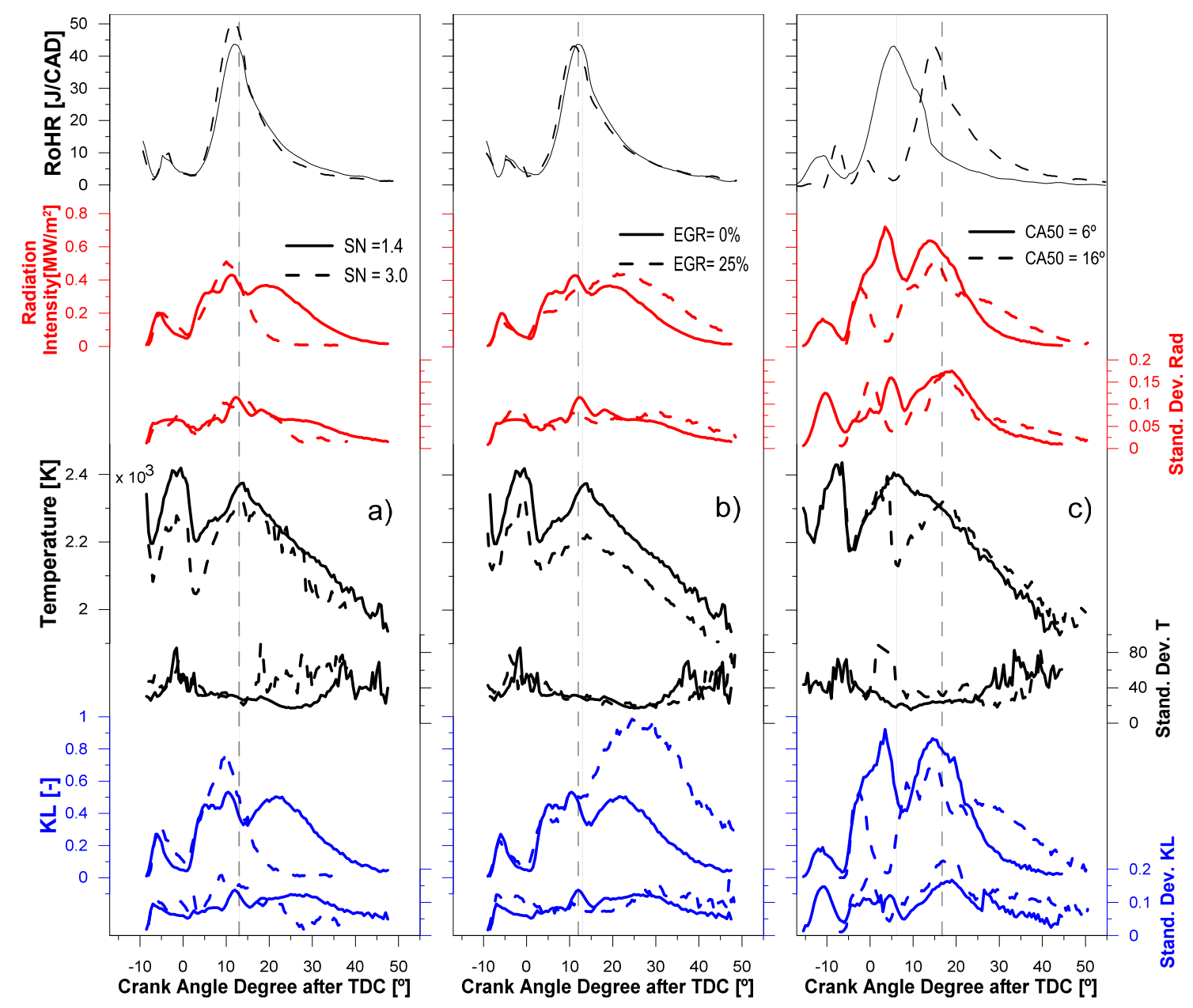

Figure 19. Temporal evolution of radiation intensity, soot temperature and KL; a) Swirl ratio effect; b) EGR effect and c) CA50 effect. For each studied case, the end of injection, is marked with a vertical line.

Considering the effect of swirl ratio, it is possible to state that an increase of swirl number implies an overall enhancement of fuel air mixing after the end of injection. Consequently there was an acceleration of the flame progression with a higher peak of RoHR and a faster decay after the end of injection. [42]. This behavior found in the RoHR was also attained in the radiation intensity. When the swirl ratio was increased, a higher peak of radiation was attained as well as a faster decay after the end of injection. Before EoI, an increase in SN resulted in higher soot formation, maybe due to spray interaction. By contrast, after the EoI, a lower KL was obtained due to an improvement in mixing process. Regarding soot temperature, quite similar values were attained. A slight increase was obtained when higher swirl ratio was proposed.

Regarding EGR effect, taking into account free spray considerations [43], it can be stated that when EGR was increased, similar equivalence ratios at lift-off length were attained. This fact implies that similar soot formation is expected. Thus, similar soot 
formation together with lower combustion temperature due to higher EGR should provide lower radiation. By contrast, considering real engine conditions as presented in the current research, it is possible to demonstrate that higher EGR implies higher peak of radiation intensity with larger radiation time and therefore higher global radiation. This behavior can be explained considering KL curves. Thus, when higher EGR rates were used, higher peaks of KL were obtained. Moreover, more time is available to form soot . Consequently higher soot formation is obtained. This fact seems to have higher impact on radiation than the reduction in soot temperature. Concerning soot temperature, an expected decrease due to the reduction in oxygen concentration was observed.

Concerning combustion phasing effect (CA50), when the injection timing is delayed with the aim of delaying CA50, greater part of the combustion process takes place during expansion stroke and therefore lower in-cylinder pressure and temperature are expected. Concerning radiation intensity, it is possible to state that when CA50 is delayed, lower radiation is attained. In particular, lower peak and slower decay is shown during the temporal evolution. Lower in-cylinder temperatures imply more time to attain more premixed combustion process with less rich equivalence ratios and therefore lower soot formation.

To compare directly the effects of swirl ratio, EGR and CA50 figure 20 presents the total radiation for the different operating conditions tested.

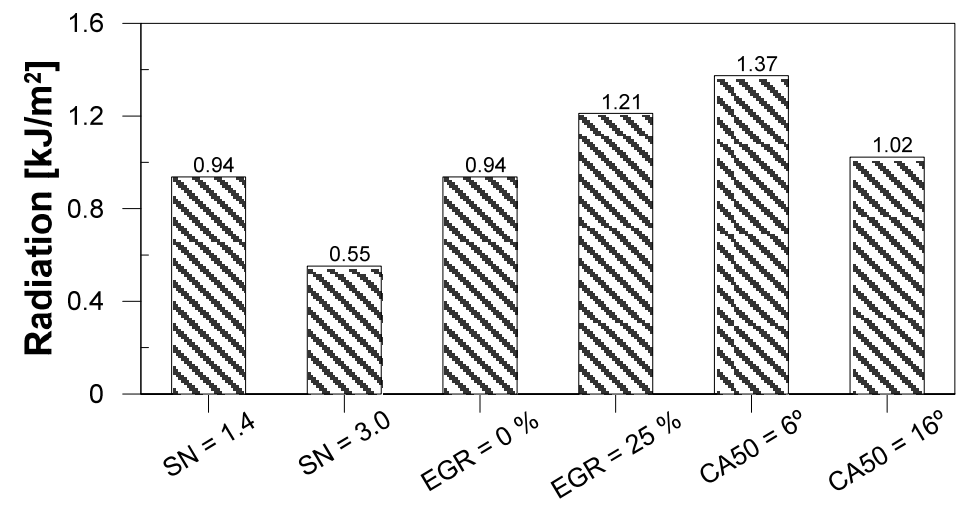

Figure 20. Total radiation considering swirl ratio, EGR and combustion phasing effects

According to figure 20, the total radiation was increased when the swirl ratio was diminished and/or EGR was increased and/or CA50 was advanced. 


\section{CONCLUSIONS}

A single cylinder optical accessible engine and a multi-cylinder engine were used to characterize in-cylinder radiation. In particular, two color method was applied using high-speed imaging and a dedicated optoelectronic pyrometer. Soot temperature and optical thickness were used to estimate the total radiation and the radiant fraction.

- Considering results obtained at optical accessible engine it can be said that optoelectronic pyrometer provides similar soot temperature and optical thickness (KL) compared with a conventional high speed imaging pyrometer. Thus, the axial evolution of the spectral intensity was characterized showing an increase when the injection pressure was decreased and/or the ambient temperature and in-cylinder gas density were increased. Coupled with this behavior, the flame lift of length was also characterized. Thus, larger values were obtained when the injection pressure was increased and/or in-cylinder gas density and temperature were decreased. The larger the lift off, lower the soot volume fraction and therefore the spectral intensity. Consequently, an increase in the radiation fraction was obtained when the injection pressure was decreased and/or the ambient temperature and in-cylinder gas density were increased. In general, the results obtained show low radiation values that range from $0.1 \%$ up to $0.75 \%$ depending on the different operating conditions tested.

- The main conclusion from the multi-cylinder production engine study can be split depending on the engine parameter sweep. Thus considering load effects it can be said that maintaining constant engine speed, the radiation intensity peak was higher when the load was increased. In addition, total radiation was defined as the radiation intensity integrated during the whole temporal evolution and as expected, it showed a clear increase when the load was increased. A clear decrease in soot temperature was attained when the engine load was decreased. KL profiles depend directly on the diffusion phase of combustion, the higher the duration of this phase, the higher the amount of soot obtained. In particular, the end of injection determined the evolution of the KL profile in terms of maximum values as well as decay. Considering swirl ratio effects it can be stated that an increase of swirl number implied an enhancement of combustion process which seems to be more prominent after the end of injection. Therefore 
a higher peak of radiation intensity with a faster decay after the end of injection was attained. Nevertheless, when total radiation was considered, an increase in swirl ratio resulted in lower total radiation. Considering KL temporal evolution results, it seems that end of injection determines an inflection point. Thus, an increase in SN resulted in higher soot formation before the EoI and lower KL after the EoI. Regarding soot temperature, quite similar values were attained independent of the swirl ratio. Taking into account EGR effects is can be demonstrated that higher EGR implies higher peak of radiation intensity with increased radiation time and therefore higher total radiation. Higher EGR rates lead to higher peaks of KL and more time available for soot formation, while soot temperature is decreased. The higher soot formation effect seems to have higher impact on radiation than the reduction in soot temperature and therefore higher total radiation was attained when higher EGR was used. Finally, considering the injection timing (combustion phasing) effects it can be stated that when CA50 was delayed, lower peak of radiation intensity was attained. This behavior was due to lower soot temperatures when the CA50 was delayed and lower soot formation since more time to achieve premixed combustion was available.

\section{ACKNOWLEDGMENTS}

The authors acknowledge General Motors Global R\&D for supporting this research.

\section{REFERENCES}

[1] Caresana, F., Bilancia, M., Bartolini C.M. Numerical method for assessing the potential of smart engine thermal management: Application to a medium-upper segment passenger car. Appl. Therm. Eng. 31(16), 3559-3568, 2011, doi:10.1016/j.applthermaleng.2011.07.017.

[2] Chalgren, R. and Allen, D. Light Duty Diesel Advanced Thermal Management. SAE Technical Paper 2005-01-2020, 2005, doi: 10.4271/2005-01-2020.

[3] Dimopoulos, P., Bacha, C., Soltica, P., Boulouchos, K.. Hydrogen-natural gas blends fuelling passenger car engines: Combustion, emissions and well-to-wheels assessment. Int. J. Hydrogen Energ. 33(23), 7224-7236, 2008, doi:10.1016/j.ijhydene.2008.07.012. 
[4] Osada, H., Uchida, N., Shimada, K., and Aoyagi, Y. Reexamination of Multiple Fuel Injections for Improving the Thermal Efficiency of a Heavy-Duty Diesel Engine. SAE Technical Paper 2013-01-0909, 2013, doi:10.4271/2013-01-0909.

[5] Neshat E., Kloshbakhti R. Effect of different heat transfer models on HCCI engine simulation. Energy conversion and management, Volume 88, December 2014, Pages 1-14.

[6] Taymaz, I. An experimental study of energy balance in low heat rejection diesel engine. Energy 31 (2-3) 364-371 2006, doi:10.1016/j.energy.2005.02.004.

[7] Morawitz, U., Mehring, J., and Schramm, L. Benefits of Thermal Spray Coatings in Internal Combustion Engines, with Specific View on Friction Reduction and Thermal Management. SAE Technical Paper 2013-01-0292, 2013, doi: 10.4271/2013-01-0292.

[8] Serrano, J., Olmeda, P., Tiseira, A., García-Cuevas, L. Importance of Mechanical Losses Modeling in the Performance Prediction of Radial Turbochargers under Pulsating Flow Conditions. SAE Int. J. Engines 6(2):729-738, 2013, doi:10.4271/2013-01-0577.

[9] Benajes, J. et al. Analysis of the combustion process, pollutant emissions and efficiency of an innovative 2-stroke HSDI engine designed for automotive applications. Appl. Therm. Eng., 58(1-2), 181-193, doi:10.1016/j.applthermaleng.2013.03.050.

[10] Benajes J., Pastor J.V., García A., Monsalve-Serrano J. An experimental investigation on the Influence of piston bowl geometry on RCCI performance and emissions in a heavy-duty engine. Energy Conversion and Management, http://dx.doi.org/10.1016/j.enconman.2015.07.047.

[11] Benajes J., Molina S., García A., Monsalve-Serrano J. Effects of Direct injection timing and Blending Ratio on RCCI combustion with different Low Reactivity Fuels. Energy Conversion and Management, Volume 99, 15 July 2015, Pages 193-209.

[12] Struwe, F.J. In-cylinder Measurement of Particulate Radiant Heat Transfer in a Direct Injection Diesel Engine. SAE Technical Paper 2003-01-0072, 2003. 
[13] Furmanski P., Banaszek J. and Wisniewski T. S. Radiation Heat Transfer in a Combustion Chamber of Diesel Engine with Partially Transparent Burnt Gas Zone. SAE Technical Paper 980504, 1998.

[14] Vogelin P. Experimental investigation of multi-in-cylinder pyrometer measurements and exhaust soot emissions under steady and transient operation of a heavy-duty Diesel engine. SAE Technical Paper 131ICE-0145, 2013.

[15] Skeen S., Manin J. and Pickett L. Quantitative Spatially Resolved Measurements of Total Radiation in High-Pressure Spray Flames. SAE Technical Paper 2014-01-1252, 2014.

[16] Flynn, P., Mizusawa, M., Uyehara, O., and Myers, P. An Experimental Determination of the Instantaneous Potential Radiant Heat Transfer within an Operating Diesel Engine. SAE Technical Paper 720022, 1972, doi:10.4271/720022.

[17] Li, X, and Wallace, J.S. In-Cylinder Measurement of Temperature and Soot Concentration Using the Two-Color Method. SAE Technical Paper 950848, 1995, doi:10.4271/950848.

[18] Tree, D.R, Svensson, K. I. Soot processes in compression ignition engines. Progress in Energy and Combustion Science 33 (2007) 272-309.

[19] Zhao, H.C., and Broughton, F. P. Determination of True Temperature and Total Radiation From Luminous Gas Flames. Ind. Eng. Chem. Anal. Ed., 4(2), pp. 166175, 1932, doi:10.1021/ac50078a004.

[20] Vattulainen, J., Nummela, V., Hernberg, R. and Kytölä, J. A system for quantitative imaging diagnostics and its application to pyrometric in-cylinder flametemperature measurements in large diesel engines. Meas. Sci. Technol., Vol. $11 \mathrm{Nr}$. 2, 2000 doi:10.1088/0957-0233/11/2/303.

[21] Musculus, P.B. M., Singh, S. and Reitz, R. D. Gradient effects on two-color soot optical pyrometry in a heavy-duty DI diesel engine. Combustion and Flame,153,216-227,2008, doi:10.1016/j.combustflame.2007.10.023.

[22] Pastor J.V., Garcia J.M., Pastor J. M., Buitrago J.E. Analysis Methodology of Diesel Combustion by Using Flame Luminosity, Two-Colour Method and LaserInduced Incandescence. SAE Technical Paper 2005-24-012, 2005. 
[23] Payri F., Lujan J.M., Martín J., Abbad A. Digital signal processing of incylinder pressure for combustion diagnosis of internal combustion engines. Mechanical Systems and Signal Processing 24 (2010) 1767-1784.

[24] DRIVVEN Stand Alone Direct Injector Driver System User's Manual October 2010. Drivven, INC. 12001 Network Blvd, 110. San Antonio, Texas 78249. Web: www.drivven.com $<$ http://www.drivven.com>.

[25] Payri F., Pablo Olmeda P., Martin J., Carreño R. A New Tool to Perform Global Energy Balances in DI Diesel Engines. SAE Technical Paper 2014-01-0665, 2014.

[26] Payri F., Olmeda P., Martín J., García A. A complete 0D thermodynamic predictive model for direct injection diesel engines. Appl. Energy 88 (12) (2011)4632e4641,http://dx.doi.org/10.1016/j.apenergy.2011.06.005.

[27] Payri F., Galindo J., Martín J., Arnau F.J. A Simple Model for Predicting the Trapped Mass in a DI Diesel Engine. SAE Technical Paper Series 2007-01-0494, 2007.

[28] Lapuerta M., Armas O., Hernandez J.J. Diagnosis of DI diesel combustion from in-cylinder pressure signal by estimation of mean thermodynamic properties of the gas. Appl. Therm. Eng. 19 (5) (1999) 513-529, http://dx.doi.org/ 10.1016/S1359-4311(98) 00075e1.

[29] F. Payri, S. Molina, J. Martín, O. Armas, Influence of measurement errors and estimated parameters on combustion diagnosis, Appl. Therm. Eng. 26 (2e3) (2006)226e236, http://dx.doi.org/10.1016/j.applthermaleng.2005.05.006.

[30] Payri F., Margot X., Gil A., Martín J. Computational Study of Heat Transfer to the Walls of a DI Diesel Engine. SAE paper 2005-01-0210, 2005.

[31] Benajes J., Olmeda P., Martín J., Carreño R. A new methodology for uncertainties characterization in combustion diagnosis and thermodynamic modelling. Appl. Therm. Eng. $71 \quad$ (2014) 389-399. http://dx.doi.org/10.1016/j.applthermaleng.2014.07.010.

[32] Payri F., Pastor J., Garcia J., Measurement Science and Technology, vol. 18, no. 8, pp. 2579-2598, 2007. 
[33] Zhao H. and Ladommatos N, Progress in Energy and Combustion Science, vol. 24, no. 3, pp. 221-255, 1998 .

[34] Hottel H. and Broughton F., Industrial and Engineering Chemistry, vol. 4, no. 2, pp. 166-175, 1932.

[35] Operating Manual Product and Guide. AVL VisioFem manual.

[36] Pickett L.M. and Siebers D.L. Soot in diesel fuel jets: effects of ambient temperature, ambient density, and injection pressure. Combustion and Flame 138 (2004) 114-135.

[37] Way RJB. Methods for determination of composition and thermodynamic properties of combustion products for internal combustion engine calculations. P I Mech Eng 1976;190:686e97.

[38] Musculus, P.B. M. Measuremets of the influence of Soot Radiation on InCylinder Tempratures and Exhaust NOx in a Heavy-Duty DI Diesel Engine. SAE Technical Paper 2005-01-0925, 2005.

[39] Soloiu V., Lewis J., Yoshihara Y., Nishiwaki K. Combustion characteristics of a charcoal slurry in a direct injection diesel engine and the impact on the injection system performance. Energy 36 (2011) 4353-4371.

[40] Arrègle J., Pastor J.V., López J.J., García A. Insights on postinjectionassociated soot emissions in direct injection diesel engines. Combustion and Flame 154 (2008) 448-461.

[41] Manin J., Pickett L.M., Skeen S. Two-Color Diffused Back-Illumination Imaging as a Time-Resolved Soot Measurements in Reacting Sprays. SAE Technical Paper 2013-01-2548, 2013.

[42] Benajes J., Molina S., García J.M., Riesco J.M. The effect of swirl on combustion and exhaust emissions in heavy-duty diesel engines. Proc. Instn Mech. Engrs Vol. 218 Part D: J . Automobile Engineering.

[43] Tao F., Liu Y., RempelEwert B. H., Foster D. E. Reitz R.D., Choi D., Miles P.C. Modeling the effects of EGR and injection pressure on soot formation in a 
high-speed direct-injection (HSDI) Diesel Engine using a Multi-Step Phenomenological Soot Model. SAE Technical Paper 2005-01-0121, 2005.

[44] Lopez J.J., García-Oliver J.M., García, A., Domenech V. Gasoline effects on spray characteristics, mixing and auto-ignition processes in a CI engine under Partially Premixed Combustion conditions. Applied Thermal Engineering 70 (2014) 996-1006. 


\section{ABBREVIATIONS}

BMEP: Brake Mean Effective Pressure

CA: Crank Angle

CMOS: Complementary Metal Oxide Semiconductor

CO2: Carbon Dioxide

DI: Direct Injection

ECN: Engine Combustion Network

EGR: Exhaust Gases Recirculation

EVC: Exhaust Valve Close

FWHM: Full Width at Half Maximum

GHG: Green House Gas

HSIP: High Speed Imaging Pyrometer

HT: Heat Transfer

$\mathrm{I}_{\mathrm{b}, \lambda}:$ Spectral Intensity of Black Body

ICE: Internal Combustion Engines

$\mathrm{I}_{\text {soot }}:$ Spectral Intensity

IVC: Inlet Valve Close

KL: Optical Thickness

$\mathrm{K}_{\mathrm{s}}$ : Conical Shape

$\mathrm{m}_{\mathrm{f}}$ : Mass of Fuel Injected

OP: Optoelectronic Pyrometer

$\mathrm{P}_{\text {inj: }}$ Injection Pressure

LHV: Lower Heating Value

RoHR: Heat Release Rate

SoI: Start of Injection

SoE: Start of Energizing

TDC: Top Dead Center 
VGT: Variable Geometry Turbocharger

$\mathrm{X}_{\mathrm{O} 2}$ : Oxygen Fraction

$\alpha$ : Absorptivity Coefficient

$\varepsilon_{\lambda}:$ Spectral Emissivity

$\lambda$ : Wavelenght

$\rho:$ Density

$\Omega$ : Solid Angle 